\title{
1 On the pitfalls of Airy isostasy and the isostatic gravity anomaly in general
}

Jon F. Kirby

School of Earth and Planetary Sciences, Curtin University, GPO Box U1987, Perth WA 6845, Australia.E-mail:j.kirby@curtin.edu.au

6

7 Received 2018 August 17; in original form 2018 February 01

\section{SUMMARY}

10 Isostatic gravity anomalies provide a measure of the Earth's gravity field free from the gravitational attractions of the topography and its isostatic compensation, most commonly represented by a variation in the depth of a compensating density contrast, for example the Moho. They are used by both geodesists and geophysicists alike, though often for different purposes. Unfortunately though, the effect of subsurface loading on the lithosphere renders transfer function (admittance) methods unusable when surface and subsurface loads coexist. Where they exist, subsurface loads are often expressed in the Bouguer anomaly but not in the topography, and it is shown here that this phase disconnect cannot be faithfully represented by either real- or complex-valued analytic admittance functions. Additionally, many studies that employ the isostatic anomaly ignore the effects of the flexural rigidity of the lithosphere, most often represented as an effective elastic thickness $\left(T_{e}\right)$, and assume only Airy isostasy, i.e. surface loading of a plate with zero elastic thickness. The consequences of such an omission are studied here, finding that failure to account for flexural rigidity and subsurface loading can result in (1) over- or underestimates of both inverted Moho depths and dynamic topography amplitude, and (2) underestimates of the size of topographic load that can be supported by the plate without flexure. An example of the latter is shown over Europe. 
26 Finally, it is demonstrated how low values of the isostatic anomaly variance can actually be biased by these anomalies having low power at the long wavelengths while still possessing high power at middle to short wavelengths, compared to the corresponding Bouguer anomaly power spectrum. This will influence the choice of best-fitting isostatic model if the model is chosen by minimization of the isostatic anomaly standard deviation.

Key words: Gravity anomalies and Earth structure; Europe; Dynamics: gravity and tectonics; Dynamics of lithosphere and mantle; Lithospheric flexure.

\section{INTRODUCTION}

According to the principle of isostasy, topographic features on the Earth's surface must be compensated to some extent by subsurface mass-density anomalies, as in Archimedes' principle. The simplest models of isostatic compensation are the Airy-Heiskanen (Airy 1855; Heiskanen 1931) and Pratt-Hayford (Pratt 1855; Hayford 1909) (e.g. Heiskanen \& Moritz 1967; Watts 2001). The Airy-Heiskanen (or just 'Airy') model compensates variations in topography by variations in the relief of the crust-mantle interface (the Moho) about a mean compensation depth, where the crust and mantle have spatially uniform densities; for example, higher topography has a thicker crust below it. In the Pratt-Hayford (or just 'Pratt') model, topographic variations are compensated by lateral variations in crustal density, with a flat compensation depth (Moho), so that higher topography is modelled as having lower density relative to its surroundings. These two models are commonly called 'local isostasy' to distinguish them from the regional isostatic model of compensation, originally proposed by Vening Meinesz (1931). 
50 The regional model is similar to the Airy model in that compensation is achieved by deflection of the Moho, where the density of the crust is constant. The difference between them lies in the flexural rigidity $(D)$ of the crust and its ability to support loads mechanically. In the Airy model, the crust has no such mechanical strength $(D=0)$; a point surface topographic load is compensated by deflection of the Moho directly underneath it and nowhere else. In the Vening Meinesz model $(D>0)$, the stresses caused by the point load are regionally distributed about the point, and the load is both compensated by the Moho deflection, and supported by the mechanical strength of the crust; the Moho deflection is thus less than it would be under Airy isostasy. Modern interpretations of the Vening Meinesz model discuss the flexure of the elastic portion of the lithosphere, being the crust and uppermost mantle, or portions thereof, rather than the crust alone, where the lithosphere 'floats' on an inviscid asthenosphere (e.g. Watts 2001). In most models, the primary density contrast providing compensation of loads is still assumed to lie at the Moho (e.g. Forsyth 1985), since the density contrast at the lithosphere-asthenosphere boundary is an order of magnitude smaller, $\sim 40 \mathrm{~kg} \mathrm{~m}^{-3}$ as opposed to $\sim 500 \mathrm{~kg} \mathrm{~m}^{-3}$ at the Moho (Cordell et al. 1991).

These isostatic compensation mechanisms can be used to apply corrections to gravity anomalies by modelling and removing the gravity effect of the subsurface mass-density anomalies compensating the topography. In the Pratt model this will be the gravity effect of the lateral density variations in the crust; in the Airy and Vening Meinesz models the correction will model the density anomalies caused by deflection of the Moho; while the Vening Meinesz model must also account for the fact that mechanical support implies a shallower compensation depth. When the isostatic correction thus derived is subtracted from the Bouguer anomaly the result is the isostatic anomaly, which should be small if the model is a fair description of the actual compensation and its parameters, and the Bouguer 
correction and/or topographic reduction have properly accounted for the presence of any mass-density anomalies above the geoid.

Non-zero isostatic anomalies show that the actual compensation mechanism differs from that of the assumed model. Such differences can be attributed to relatively minor concerns such as incorrect choice of densities or compensation depths in the model, or major concerns such as a wrong choice of model where the effects of mechanical or dynamic support are misinterpreted as under- or overcompensation in a local isostatic model (e.g. Simpson et al. 1986). However, non-zero isostatic anomalies can also reveal compensated intralithospheric density anomalies with no topographic expression; regional variations in effective elastic thickness $\left(T_{e}\right)$, or loading at one value of $T_{e}$ followed by erosional unloading at another; mantle density variations and the dynamic support of the lithosphere due to convective processes in the upper mantle; the viscoelastic response to time-varying loads, such as glacial isostatic adjustment; and the deeper signals from the mantle and core (e.g. Forsyth 1985; Simpson et al. 1986; Ussami et al. 1993; Kaban et al. 2004).

Geophysicists have largely used isostatic anomalies for investigations of Earth structure. Some of these studies have assumed Airy isostasy when computing isostatic anomalies (e.g. Karner \& Watts 1982; Simpson et al. 1986; Ussami et al. 1993; Kaban et al. 1999; Tiwari et al. 2003). Other workers have invoked the flexural rigidity (or its geometric analogue, the effective elastic thickness, $T_{e}$ ) in isostatic anomaly computation (e.g. Walcott 1970; Dorman \& Lewis 1972; Karner \& Watts 1983; Watts et al. 1995; Jordan \& Watts 2005; Harmon et al. 2006; Wyer \& Watts 2006; Watts \& Moore 2017). Several studies have sought to estimate lithospheric parameters such as interface depths and densities by minimizing the isostatic anomaly variance (e.g. Sünkel 1985; Martinec 1993, 1994a,b; Kaban et al. 2004; Sjöberg 
2009; Bagherbandi \& Sjöberg 2012), a topic that will be investigated in Section 3.

Additionally, many studies assume Airy isostasy when computing dynamic topography (e.g. England \& Molnar 2015; Molnar et al. 2015), a topic that will be addressed in Section 4.3.

In the geodetic community, however, workers have largely persisted with Airy, and to a lesser extent Pratt models of local isostasy (e.g. Pavlis \& Rapp 1990; Martinec 1994b; Balmino et al. 2012; Hirt et al. 2012; Aitken et al. 2015), often because their analyses concern very large, even global study areas where Airy or Pratt models would be more appropriate in describing isostasy than regional models. However, the inability of the Airy model to correctly represent the actual state of compensation is well documented. For instance, Lewis \& Dorman (1970) and Dorman \& Lewis (1972) assumed Airy isostasy and inverted an isostatic response function to find the density contrasts compensating the North American topography. In addition to the expected shallow positive density contrast their model required an unrealistic negative density contrast (i.e., a decrease in density with depth) within the upper mantle ( 400 km depth). Banks et al. (1977) adequately remodelled Dorman \& Lewis's (1972) data using a regional compensation model with a non-zero elastic thickness, concluding that any local model with negative densities can be replaced by a regional model with compensating positive densities at shallower depths (Banks et al. 1977; Simpson et al. 1986; Cordell et al. 1991).

Oceanic lithosphere provides cases where local isostasy does not apply. As Sünkel (1985) notes, oceanic crust is typically $7 \mathrm{~km}$ thick on average but much deeper compensation levels are required to prevent the oceanic antiroots of the Airy model extending above the seafloor (e.g. Rapp 1982). In contrast, the mechanical support provided by regional isostatic models enables compensation levels to be placed at much more realistic depths, closer to the Moho. 
For example, Louden \& Forsyth (1982) analysed the compensation of the Kane fracture zone, and where the Airy model required a $30 \mathrm{~km}$ thick oceanic crust, a flexural model with a more realistic $6 \mathrm{~km}$ thick crust gave a better fit to observed admittance data. Nevertheless, Prattstyle compensation is thought to apply at mid-ocean ridges, though with the density increase away from the ridge occurring in the sub-crustal mantle rather than the crust, while Airy isostasy would apply at continent-ocean boundaries (Watts 2007).

And recently, using spherical harmonics, Watts \& Moore (2017) fitted two isostatic models to the mid- to high-degrees $(12 \leq n \leq 400)$ of the global EGM2008 free air anomaly (Pavlis $e t$ al. 2012). When using an Airy model the best fit was provided by an unrealistic compensation (Moho) depth of $61 \mathrm{~km}$. In contrast, a better fit was obtained with a flexural model of compensation depth $30 \mathrm{~km}$ and $T_{e}=34 \mathrm{~km}$.

Hence, this study aims to test the limits of the applicability of the Airy isostatic compensation model, but also comments on the utility of isostatic gravity anomalies in general. In Section 2 some theory is presented regarding the computation of isostatic anomalies. In Section 3, synthetic Bouguer anomaly and topography models are generated with known plate parameters (such as compensation depth, elastic thickness, etc.); isostatic anomalies are then computed from these synthetic models over a whole range of plate parameters, using the spectral methods described in Section 2. In this fashion many assumptions regarding isostatic models and gravity anomalies can be tested. Section 4 then discusses the implications of the findings in Section 3, but also comments on the isostatic and dynamic support of surface topography in the context of Airy versus flexural isostasy.

\section{ESTIMATION OF ISOSTATIC GRAVITY ANOMALIES}




\subsection{Methods favoured by geophysicists}

151 The isostatic anomaly $\left(\Delta g_{I}\right)$ is the difference between the Bouguer anomaly $\left(\Delta g_{B}\right)$ and the 152 gravitational attraction of the compensation model $\left(\delta g_{C}\right)$ : $\Delta g_{I}=\Delta g_{B}-\delta g_{C}$

154

Dorman \& Lewis (1970) proposed that the Earth acts as a linear filter, and given an observed (post-flexural) topography, $h$, it was possible to determine the gravitational effect of the isostatic compensation of that topography by filtering the topography with an 'isostatic response function', $q$. In the 1-D Cartesian space $(x)$ domain they wrote

$\delta g_{C}(x)=q(x) * h(x)$

where the * indicates space-domain convolution. Hence, by the convolution theorem:

$\delta g_{C}(x)=\mathbf{F}^{-1}[Q(k) H(k)]$

where $\mathbf{F}^{-1}$ is the inverse Fourier transform operator, $k$ is wavenumber (spatial frequency), and $Q=\mathbf{F}[q]$ is the admittance which is the wavenumber-domain transfer function from topography to gravity, discussed below. Thus, eq. (1) can be written as

$\Delta g_{I}=\Delta g_{B}-\mathbf{F}^{-1}[Q H]$

While Dorman \& Lewis (1970) called $\Delta g_{I}$ the "geologic effect", Lewis \& Dorman (1970) identified it with the isostatic anomaly, as did Watts (1978), McNutt (1980), Simpson et al. (1986), and Kaban et al. (1999), who all used such transfer function techniques. Lewis \& Dorman (1970) also tested eq. (2) for non-linear terms in the topography, $h$, by correlating the resultant isostatic anomaly with terms $h^{n}$, for $n=2-5$, finding insignificant correlation in their North American study area.

Using equations of flexure and Parker's (1972) formula, one can derive analytic equations for the theoretical admittance for many loading models, for use in eq. (4) (e.g. Kirby 2014). 
174 Those considered in this study are described next. The expression for the Bouguer admittance 175 for Airy isostasy is:

$176 Q_{A}(k)=-2 \pi \mathcal{G} \Delta \rho_{0} e^{-k z_{m}}$

177 (e.g. Forsyth 1985; Watts 2001) where $\mathcal{G}$ is the gravitational constant (Table 1 ), $z_{m}$ is the

178 depth to the compensating interface (commonly assumed to be the Moho), and $\Delta \rho_{0}=\rho_{c}-\rho_{f}$

179 where $\rho_{c}$ is the density of an incompressible single-layer crust and $\rho_{f}$ is the density of the 180 overlying fluid, either air or water.

181

182

More general loading models consider the flexural rigidity of the lithosphere, $D$, which is most commonly expressed in terms of an effective elastic thickness $\left(T_{e}\right)$ where

$184 \quad D=\frac{E T_{e}^{3}}{12\left(1-v^{2}\right)}$

(e.g., Watts 2001) and where $E$ is Young's modulus and $v$ is Poisson's ratio (see Table 1 for the values of these constants). The elastic lithosphere may include numerous crustal layers and the uppermost mantle, depending on the tectonic regime and rheological properties of these strata (Burov \& Diament 1995). Although most flexural models place the depth of compensation at the Moho (being a compositional boundary with a large density contrast), the elastic lithosphere may extend into the uppermost mantle where its boundary with the underlying asthenosphere is rheological in nature (with a much lower density contrast as noted in Section 1). It should be noted that $T_{e}$ does not, in general, describe a physical thickness or depth - rather it is a geometric analogue of the flexural rigidity - though under certain conditions, $T_{e}$ can equal the mechanical thickness of the lithosphere (e.g. Burov \& Diament 1995). 
Banks et al. (1977) derived an expression for the Bouguer admittance corresponding to initial subaerial loading on the surface of a plate with non-zero flexural rigidity ('surface' or 'top loading'):

$$
Q_{T}(k)=-2 \pi \mathcal{G} \Delta \rho_{0} e^{-k z_{m}}\left(1+\frac{D k^{4}}{g \Delta \rho_{1}}\right)^{-1}=-2 \pi \mathcal{G} \Delta \rho_{0} e^{-k z_{m}} \xi(k)^{-1}
$$

where $g$ is the gravity acceleration, $\Delta \rho_{1}=\rho_{m}-\rho_{c}$, and $\rho_{m}$ is the density of an inviscid mantle underlying the crust. Eq. (7) defines the variable $\xi(k)$. Surface loading constitutes an initial load emplaced at the Earth's topographic surface by, for example, orogenesis or volcanism. A second flexural model considers loading that takes place within the lithosphere, for instance, from magmatic underplating, igneous intrusions, or during sedimentary basin formation. McNutt (1983) derived a Bouguer admittance equation describing the case when initial loading occurs within the plate ('subsurface' or 'bottom loading'):

$Q_{B}(k)=-2 \pi \mathcal{G} \Delta \rho_{0} e^{-k z_{m}}\left(1+\frac{D k^{4}}{g \Delta \rho_{0}}\right)=-2 \pi \mathcal{G} \Delta \rho_{0} e^{-k z_{m}} \phi(k)$

which defines the variable $\phi(k)$.

Forsyth (1985) unified the surface and subsurface loading regimes by assuming independence of the initial loading processes. From his formulation an expression for the 'combined loading' Bouguer admittance can be derived:

$$
Q_{T B}(k)=-2 \pi \mathcal{G} \Delta \rho_{0} e^{-k z_{m}}\left(\frac{\xi+\phi f^{2} r^{2}}{\xi^{2}+f^{2} r^{2}}\right)
$$

(e.g. Ito \& Taira 2000) where $r=\Delta \rho_{0} / \Delta \rho_{1}$, and where $f(k)$ is the ratio of the initial subsurface to surface load amplitudes (Forsyth 1985). Considering uniform (wavenumberindependent) values of $f$, when $f=0$ eq. (9) becomes eq. (7) and describes surface-only initial loading; when $f \rightarrow \infty$, eq. (9) becomes eq. (8) and describes subsurface-only initial loading. In 
practice, $f(k)$ is computed from the recovered initial loads in Forsyth's (1985) method of $T_{e}$ estimation, though a uniform value of $f$ can be used in theoretical analytic admittance equations such as eq. (9) (e.g. Kirby 2014). Note that when $T_{e}=0 \mathrm{~km}$, the parameters $\xi$ and $\phi$, eqs (7) and (8), both equal 1 and the combined admittance, $Q_{T B}$ in eq. (9), reduces to the Airy admittance formula, eq. (5), showing that the effects of surface and subsurface loading upon a zero-rigidity plate are indistinguishable.

\subsection{Methods favoured by geodesists}

In the geodetic community, the problem is typically framed in terms of a spherical harmonic expansion of the topography, with derivation of expressions for the gravitational potential of the topography and its isostatic compensation derived from Newton's law of gravitation. The potential of the compensation has invariably been derived assuming Airy isostasy (e.g. Kaula 1967; Lachapelle 1976; Rapp 1982, 1989; Rummel et al. 1988; Kuhn 2003), though some researchers have considered the effects of flexural rigidity in their models, both indirectly (e.g. Sünkel 1985; Rummel et al. 1988; Abd-Elmotaal 1993; Kuhn 2003), and directly (e.g. Watts \& Moore 2017).

In their formulations, Sünkel (1985) and Rummel et al. (1988) use a Gaussian smoothing operator to generalise the Airy compensation model to the regional (Vening Meinesz) model, rather than employing an expression derived from physical principles, such as $\xi$ in eq. (7), though Rummel et al. (1988) do note the correspondence. Both studies estimate the parameters of the Gaussian function using least squares minimization of the resultant isostatic anomaly. Abd-Elmotaal (1993) and Kuhn (2003) both compute Vening Meinesz isostatic anomalies using space domain solutions of the plate bending equations, following Brotchie \& Silvester (1969). It should be noted, however, that if computation areas are small enough so 
that Earth curvature effects are minimal, then spherical solutions of the plate bending equations should give identical results to planar solutions.

A technique that has reappeared in the literature in the past decade is a development of a concept originally proposed by Vening Meinesz (1931) that Moho depths can be obtained from the Bouguer anomaly. This so-called "inverse problem of isostasy" was built upon by Moritz (1990) and later Sjöberg (2009) who dubbed it the VMM (Vening Meinesz-Moritz) inverse problem. As noted by Moritz (1990) the method is the spherical equivalent of Parker's (1972) planar method to determine the gravity field due to an undulating, subsurface density contrast - or rather its inverse. However, despite the name 'Vening Meinesz' implying regional isostatic compensation, the VMM (and Parker) methods make no assumptions about, or even invoke, a particular method of isostatic compensation. Thus the method, while useful, cannot be said to describe any state of isostasy because it simply assumes that the entire Bouguer anomaly is due solely to undulations of the Moho density contrast; the surface topography - essential to any isostatic model - does not feature in the formulation. Recently, Eshagh (2016) showed that the VMM method is a generalisation of the Airy-Heiskanen model, while Eshagh (2018) has attempted a reconciliation of the VMM method with more established methods of modelling flexural isostasy.

\section{TESTS ON SYNTHETIC ISOSTATIC ANOMALIES}

\subsection{Generation of the synthetic data}

In order to test how well the isostatic anomaly can be retrieved from real data, one can use synthetic plate models with known parameters. Since the work of Macario et al. (1995), synthetic testing of $T_{e}$-estimation methods is now well-established (see Kirby (2014) for a summary). Initial surface and subsurface loads are represented by random, fractal surfaces 
269 (Saupe 1988; Macario et al. 1995), and for uniform- $T_{e}$ plates the post-loading Bouguer

270 anomaly and surface topography are found by solving the flexural equation with the Fourier

271 transform (e.g. Kirby 2014). Unless otherwise noted, in all experiments here the synthetic

272 models were generated using a single-layer crust of density $2800 \mathrm{~kg} \mathrm{~m}^{-3}$ and thickness $35 \mathrm{~km}$, 273 overlying a mantle of density $3300 \mathrm{~kg} \mathrm{~m}^{-3}$ (Table 1). When invoked, the initial subsurface

274 load was emplaced at the base of the crust, $35 \mathrm{~km}$ depth.

275

276

Synthetic Bouguer anomaly and topography pairs were generated from combined loading on plates with $T_{e}$ and $f$ values described in Sections 3.2 and 3.3, following Macario et al. (1995).

Since the quantity $f$ is unbounded $[0, \infty)$ results are presented in terms of $F$ which is bounded $[0,1]$ and is the fraction of the initial subsurface load to the total initial load amplitude:

$280 \quad F=\frac{f}{1+f} \quad f=\frac{F}{1-F}$

281 Surface-only initial loading is given by $f=0$ and $F=0$ at all wavenumbers; subsurface-only initial loading is given by $f=\infty$ and $F=1$ at all wavenumbers; equal combined loading is given by $f=1$ and $F=0.5$ at all wavenumbers.

Once the Bouguer anomaly and topography pairs were generated, the compensation attraction $\left(\delta g_{C}\right)$ was computed from eq. (3) by multiplying the final topography Fourier transform $(H)$ by a theoretical Bouguer admittance function $\left(Q_{t h}\right)$, and inverse Fourier transforming, thus

$\delta g_{C}(\mathbf{x})=\mathbf{F}^{-1}\left[Q_{t h}(k) H(\mathbf{k})\right]$

where $Q_{t h}$ could be any of the analytic functions given by eqs (5), (7), (8) or (9). Note that isotropic admittances were used, as functions of $k=|\mathbf{k}|$. The parameters of the admittance functions (crust and mantle densities and crustal thickness) were identical to those of the synthetic model (unless otherwise specified). An isostatic anomaly $\left(\Delta g_{I}\right)$ was then recovered 
by subtracting the compensation attraction from the synthetic model Bouguer anomaly as in eq. (4). Hence, because there are no non-flexural signals in the synthetic Bouguer anomaly and topography, if the correct compensation model (admittance function) is chosen then the compensation attraction should exactly reproduce the Bouguer anomaly, yielding uniformly zero isostatic anomalies.

\subsection{Tests of varying $T_{e}$ and $F$}

Here, 10,100 synthetic Bouguer anomaly and topography pairs were generated from combined loading on plates with $T_{e}$ ranging from 0 to $100 \mathrm{~km}$, in steps of $1 \mathrm{~km}$ (101 values), and $F$ ranging from 0 to 0.99 , in steps of 0.01 (100 values).

\subsubsection{Assuming Airy isostasy}

In the first test ('test A'), the compensation attraction was computed for each of the 10,100 synthetic models from its topography using the Airy isostatic admittance function, i.e.

$\delta g_{C}=\mathbf{F}^{-1}\left[Q_{A} H\right]$ with $Q_{A}$ given by eq. (5). The densities and compensation depth, $z_{m}$, were set equal to the synthetic model values, given above. The isostatic anomaly corresponding to a synthetic model $\left(F, T_{e}\right)$ value was then computed using eq. (4), and its standard deviation $\left(\sigma_{I A}\right)$ determined. Rather than plotting the standard deviations directly, they were normalized (to $\left.\bar{\sigma}_{I A}\right)$ by the Bouguer anomaly standard deviation at the model $\left(F, T_{e}\right)$ value and then plotted, shown in Fig. 1(a). This normalization was performed to place a proper perspective on apparently large isostatic anomalies, which might not be large compared to the corresponding Bouguer anomalies. Thus $\bar{\sigma}_{I A}$ is interpreted as the error in using the chosen compensation model, in this case the Airy model, i.e. assuming $T_{e}=F=0$, when the reality is that $T_{e}$ and $F$ are not necessarily zero. As noted in the caption to Fig. 1, the maximum value 
317 of $\bar{\sigma}_{I A}$ in Fig. 1(a) is 2.14, occurring when the model $T_{e}$ is $100 \mathrm{~km}$ and there is no subsurface load $(F=0)$. An alternative way of phrasing this is that the total amplitude of the isostatic anomaly at these $T_{e}$ and $F$ values is 214 per cent that of the corresponding Bouguer anomaly.

Fig. 1(a) shows that when the synthetic models were generated with $T_{e}=0 \mathrm{~km}$ (for any value of the initial subsurface load fraction $F$ ), the isostatic anomalies were uniformly zero, confirming that the compensation attraction perfectly reproduces the Bouguer anomaly, and that the method used to recover isostatic anomalies performs adequately. Recall from Section 2.1 that when $T_{e}=0 \mathrm{~km}$, surface and subsurface loading are indistinguishable in their results, explaining why the locus of zero standard deviation extends from $F=0$ to $F=1$.

Fig. 1(a) suggests that, when the increased power of the Bouguer anomalies is accounted for, the Airy model is appropriate for many combinations of the plate's actual $T_{e}$ and $F$ values ( $\bar{\sigma}_{I A}<10$ per cent, for example). But both of these interpretations are misleading, as Fig. 2(a) shows, which plots the power spectra of the Bouguer and isostatic anomalies. Fig. 2(a) demonstrates that in regions of the $\left(F, T_{e}\right)$-space where $\bar{\sigma}_{I A}$ is low but $T_{e}>0$ and $F$ is high (e.g. $T_{e}=25 \mathrm{~km}, F=0.75$ ), the low values of $\bar{\sigma}_{I A}$ are caused by low relative isostatic anomaly power at mid-to-long wavelengths only, and at mid-to-short wavelengths, the Bouguer and isostatic anomalies actually have equal power. That is, the low values of $\bar{\sigma}_{I A}$ in Fig. 1(a) are biased by the large difference in long wavelength power. And because the Earth's gravity and topography naturally have red power spectra (high power at long wavelengths, low power at short), the high isostatic anomaly power at short wavelengths, relative to the Bouguer anomaly, contributes much less to the overall whole-spectrum power difference, by several orders of magnitude. Thus, minimization of the isostatic anomaly 
standard deviation alone (as done by several studies, noted in Section 1) will give misleading conclusions as to the actual state of compensation/support, even when the Bouguer anomaly standard deviation is accounted for. Instead, the spectra of Bouguer and isostatic anomalies over a region should be compared (and one should use Bouguer and not free air anomalies in the comparison since the gravity effect of the topography has been removed when generating both Bouguer and isostatic anomalies - making them compatible - but not removed from free air anomalies). And it is only when the isostatic anomaly power spectrum is much less than that of the Bouguer anomaly at all wavelengths that the conclusion should be made that the assumed compensation mechanism is a faithful representation of the actual compensation mechanism. Estimates of the isostatic parameters (e.g. $\left.T_{e}\right)$ needed to choose or refine the compensation model can be readily obtained from spectral methods (e.g. Kirby 2014).

Fig. 2(a) shows that when subsurface loading dominates $(F>0.5)$ the Airy isostatic anomalies have equal power to the Bouguer anomalies at mid-to-short wavelengths, even for relatively low-rigidity plates $\left(T_{e} \leq 25 \mathrm{~km}\right)$. Furthermore, their spectral content becomes higher-power and longer-wavelength as $T_{e}$ increases. If the plate is strong and $F$ close to 1 , the initial subsurface loads will not cause a surface (topographic) deflection and their presence will not be measurable in the topography Fourier transform, $H$; therefore, the compensation attraction, $\mathbf{F}^{-1}\left[Q_{A} H\right]$, will be small, reflecting only any low-amplitude initial surface loads that may be present. Since the Bouguer anomaly will be large, due to the large subsurface loads, the isostatic anomaly will also be large.

Fig. 2(a) also shows that, when surface loading dominates $(F<0.5)$, the Airy isostatic anomalies can have greater power than the Bouguer anomalies at the shorter wavelengths, a phenomenon that becomes more pronounced when $T_{e}$ is large and subsurface loading is 
reduced. In this case, the surface loads are supported by the plate's rigidity, so $H$ has higher power than it would on a weak plate, leading to an excess of power in the compensation attraction by virtue of $\mathbf{F}^{-1}\left[Q_{A} H\right]$, which propagates into the isostatic anomalies.

\subsubsection{Assuming surface loading}

In the second test ('test B'), the compensation attraction was computed for each of the 10,100 synthetic models from its topography using the surface-loading admittance function, i.e. $\Delta g_{C}=\mathbf{F}^{-1}\left[Q_{T} H\right]$ with $Q_{T}$ given by eq. (7) using the $T_{e}$ value of the synthetic model. The densities and compensation depth, $z_{m}$, were set equal to the synthetic model values, given above. The isostatic anomaly was then computed using eq. (4), and its normalized standard deviation determined and plotted in Fig. 1(b) at the location given by the model $\left(F, T_{e}\right)$ value. The normalized standard deviation is interpreted here as the error in assuming only initial surface loading; i.e., using the correct $T_{e}$, but assuming $F=0$, when the reality is that $F$ is not necessarily zero. As noted in the caption to Fig. 1, the maximum value of $\bar{\sigma}_{I A}$ in Fig. 1(b) is 0.36 , occurring when the model $T_{e}$ is $100 \mathrm{~km}$ and there is almost no surface load $(F=0.99)$. So whereas the assumption of Airy isostasy gave rise to isostatic anomalies having amplitudes at 214 per cent of the Bouguer anomaly, when surface-only loading is assumed the isostatic anomalies are much smaller, reaching only 36 per cent of the Bouguer anomaly amplitude.

First, Fig. 1(b) shows that when the synthetic models were generated with $F=0$ (for any value of $T_{e}$ ), the isostatic anomalies were uniformly zero, showing that the compensation attraction perfectly reproduces the Bouguer anomaly, and that the method used to recover isostatic anomalies performs adequately as long as $T_{e}$ is known. Zero isostatic anomalies also 
occur when $T_{e}=0 \mathrm{~km}$, for any value of $F$ because surface and subsurface loading are indistinguishable in their results, as explained before.

As discussed above, the power spectra reveal more information than the standard deviation plots. The power spectra for test B are shown in Fig. 2(b). When initial loading is more surface than subsurface $(F<0.5)$, a comparison of Figs $2(a)$ and $2(b)$ shows that the assumption of surface loading with a knowledge of the actual $T_{e}$ generally results in lowerpower isostatic anomalies than the assumption of Airy isostasy, especially in the mid-to-short wavelengths. Not shown in Fig. 2(b) are the isostatic anomaly spectra for $F=0$, which are uniformly zero at all wavelengths, as expected.

In contrast, when initial loading is more subsurface than surface $(F>0.5)$, the assumption of surface loading results in higher-power long wavelength isostatic anomalies compared to Airy isostasy, by as much as two orders of magnitude. In conclusion, knowledge of $T_{e}$ will not necessarily provide an improved compensation model.

\subsubsection{Assuming combined loading}

In the third test ('test C'), the compensation attraction was computed for each of the 10,100 synthetic models from its topography using the combined-loading admittance function, i.e. $\delta g_{C}=\mathbf{F}^{-1}\left[Q_{T B} H\right]$ with $Q_{T B}$ given by eq. (9) using the $T_{e}$ and $F$ values of the synthetic model. The densities and compensation depth, $z_{m}$, were set equal to the synthetic model values, given above. The isostatic anomaly was then computed using eq. (4), and its normalized standard deviation determined and plotted in Fig. 1(c) at the location given by the model $\left(F, T_{e}\right)$ value. The normalized standard deviation is interpreted here as the error in assuming combined loading; i.e., using the correct $T_{e}$ and $F$. In other words, there should be no error. 
416 In tests A and B the non-zero isostatic anomalies were explained as arising from a lack of

417 knowledge about the actual compensation mechanisms; incorrectly assuming Airy isostasy in

418 test $\mathrm{A}$, and surface-loading in test B, when the reality was combined loading of a rigid plate.

419 However, in test $\mathrm{C}$, since the model $T_{e}, F, z_{m}$ and density values are known and used to

420 compute the compensation attraction, it would be reasonable to expect that the correct

421 compensation model (the correct theoretical admittance) had been used, giving uniformly

422 zero $\bar{\sigma}_{I A}$ over Fig. 1(c). While this is not seen, the $\bar{\sigma}_{I A}$ values are somewhat smaller for test

$423 \mathrm{C}$ than test B [with a maximum value of $\bar{\sigma}_{I A}$ in Fig. $1(\mathrm{c})$ of 30 per cent at $T_{e}=100 \mathrm{~km}, F=$

4240.3 , suggesting that some knowledge of subsurface loading is an improvement over the assumption of surface loading only, especially for almost complete surface-only $(F<0.05)$ and subsurface-only $(F>0.95)$ initial loading. Nevertheless, when the power spectra are analysed (Fig. 2c), the short-wavelength isostatic anomaly power is considerable for $T_{e} \geq 10$ $\mathrm{km}$ and $F \geq 0.25$. Compared to the results from Airy isostasy (test A, Fig. 2a), the longwavelength isostatic anomaly power from combined loading is several orders of magnitude lower when $F$ is low or high, but not with intermediate values $(0.25 \leq F \leq 0.75)$ when the power is similar at all wavelengths. Importantly, the power is not uniformly zero, when it 432 should be.

434 Evidently, further analysis is required, and this analysis should focus upon the role of subsurface loading, since in the tests conducted so far the isostatic anomaly power increases with increasing subsurface load amplitude, for a given $T_{e}$. The investigation should also focus

437 on the admittance, since, as discussed in Section 3.2.1, the lack of subsurface load signal in the surface topography transform, $H$, for high $T_{e}$ leads to inaccurate compensation attractions 
439

440

441

442

443

444

445

446

447

448

449

450

451

452

453

454

455

456

457

458

459 (12) will be complex, as shown ahead.

$$
460 \quad Q_{T B}{ }^{\prime}=\frac{\left\langle\left(Q_{T} H_{T}+Q_{B} H_{B}\right)\left(H_{T}+H_{B}\right)^{*}\right\rangle}{\left\langle\left(H_{T}+H_{B}\right)\left(H_{T}+H_{B}\right)^{*}\right\rangle}
$$

(e.g. Forsyth 1985) where $G$ is the Fourier transform of the Bouguer anomaly, $H$ is the

Fourier transform of the topography, the asterisk denotes complex conjugation, and the angle brackets indicate some averaging process which can give an isotropic (1-D) $Q(k)$, or an anisotropic (2-D) $Q(\mathbf{k})$ (see Kirby (2014) for a summary). In general, the numerator of eq.

Consider two noise-free, independent processes, for instance surface ( $\mathrm{T}$ ) and subsurface (B) loading. Let $G_{T}=Q_{T} H_{T}$, and $G_{B}=Q_{B} H_{B}$, in the Fourier domain, where the $Q$ s are realvalued, given by eqs (7) and (8), and all variables are functions of wavevector $\mathbf{k}$. Then the final gravity will be $G=G_{T}+G_{B}$, and the final topography will be $H=H_{T}+H_{B}$ (Forsyth 1985). Substituting these expressions in eq. (12), the combined admittance is 
461 Letting $H_{T}=\left|H_{T}\right| e^{i \alpha_{T}}$ and $H_{B}=\left|H_{B}\right| e^{i \alpha_{B}}$, where the phases $\alpha$ are functions of wavenumber,

462 it can be shown that the combined admittance is indeed complex:

463

$$
Q_{T B}{ }^{\prime}=\frac{\left\langle Q_{T}\left|H_{T}\right|^{2}+Q_{B}\left|H_{B}\right|^{2}+\left(Q_{T}+Q_{B}\right)\left|H_{T}\right|\left|H_{B}\right| \cos \theta\right\rangle+i\left\langle\left(Q_{T}-Q_{B}\right)\left|H_{T}\right|\left|H_{B}\right| \sin \theta\right\rangle}{\left\langle\left|H_{T}\right|^{2}+\left|H_{B}\right|^{2}+2\left|H_{T}\right|\left|H_{B}\right| \cos \theta\right\rangle}
$$

464 where the phase difference $\theta=\alpha_{T}-\alpha_{B}$ is also wavenumber-dependent.

465

466 Eq. (14) can be turned into a theoretical analytic equation for admittance in the following

467 manner. Write eq. (14) as

$468 \quad Q_{T B}^{\prime}=\frac{Q_{1}^{\prime}+Q_{2}^{\prime}}{Q_{3}^{\prime}}$

and treat the real part of the numerator $\left(Q_{1}^{\prime}\right)$ initially:

470

$$
Q_{1}^{\prime}=\left\langle Q_{T}\left|H_{T}\right|^{2}+Q_{B}\left|H_{B}\right|^{2}+\left(Q_{T}+Q_{B}\right)\left|H_{T}\right|\left|H_{B}\right| \cos \theta\right\rangle
$$

471 In his paper, Forsyth (1985) introduced the initial loading ratio, $f$, as the ratio of the weight of

472 the applied load at the Moho to that of the applied load on the surface, and expressed it as

$$
f(\mathbf{k}) r\left|H_{T}(\mathbf{k})\right|=\xi\left|H_{B}(\mathbf{k})\right|
$$

474 where $\xi$ is defined in eq. (7), and $r$ in Section 2.1. Thus, using eq. (17), eq. (16) becomes

$$
Q_{1}^{\prime}=\left\langle Q_{T}\left|H_{T}\right|^{2}+Q_{B} f^{2} r^{2} \xi^{-2}\left|H_{T}\right|^{2}+\left(Q_{T}+Q_{B}\right) f r \xi^{-1}\left|H_{T}\right|^{2} \cos \theta\right\rangle
$$

476 The averaging is typically performed over the $360^{\circ}$ of an annulus in the wavevector, $\mathbf{k}$, space,

477 with many annuli spanning the space, yielding an isotropic quantity as a function of

478 wavenumber modulus, $k=|\mathbf{k}|$. The wavenumber-dependent functions $\xi, Q_{T}$ and $Q_{B}$ are smooth and slowly varying analytic functions, so if the annuli are very narrow, spanning a very small range of $k$, they can be treated as constants and taken out of the averaging. Thus eq. (18) can be written as 
482

$Q_{1}^{\prime}=Q_{T}\left\langle\left|H_{T}\right|^{2}\right\rangle+Q_{B} r^{2} \xi^{-2}\left\langle f^{2}\left|H_{T}\right|^{2}\right\rangle+\left(Q_{T}+Q_{B}\right) r \xi^{-1}\left\langle f\left|H_{T}\right|^{2} \cos \theta\right\rangle$

483 Taking the loading ratio, $f(\mathbf{k})$, and phase difference, $\theta(\mathbf{k})$, out of the averaging procedure is

484 perhaps harder to justify since they are dependent on the data and most likely will not be

485 smooth and slowly varying but instead potentially highly variable functions of wavevector $\mathbf{k}$.

486 Additionally, the phase difference contains the phase information of $H_{T}$ and $H_{B}$. Therefore in

487 order to obtain an all-purpose analytic expression for $Q_{T B}{ }^{\prime}$, one that is data-independent akin

488 to eqs (7) - (9), one must make three assumptions. First, Kirby \& Swain (2009) reasoned that

489 if the amplitudes and phases of the data are independent then one can write

490

$\left\langle f(\mathbf{k})\left|H_{T}(\mathbf{k})\right|^{2} \cos \theta(\mathbf{k})\right\rangle \approx\left\langle f(\mathbf{k})\left|H_{T}(\mathbf{k})\right|^{2}\right\rangle\langle\cos \theta(\mathbf{k})\rangle$. Their second assumption was that if

491 the amplitudes of the surface and subsurface processes are independent then $\left\langle f(\mathbf{k})\left|H_{T}(\mathbf{k})\right|^{2}\right\rangle$

$492 \approx f(k)\left\langle\left|H_{T}(\mathbf{k})\right|^{2}\right\rangle$. Third, they assumed that if the phase difference is independent of

493

azimuth, then $\langle\cos \theta(\mathbf{k})\rangle \approx \cos \theta(k)$. Hence, with these assumptions, eq. (19) becomes

494

$Q_{1}^{\prime}=\left[Q_{T}+Q_{B} f^{2} r^{2} \xi^{-2}+\left(Q_{T}+Q_{B}\right) f r \xi^{-1} \cos \theta\right]\left\langle\left|H_{T}\right|^{2}\right\rangle$

495

496 Applying the same treatment to the imaginary part of the numerator of eq. (14) and its

497 denominator gives

498

$Q_{2}^{\prime}=i\left(Q_{T}-Q_{B}\right) f r \xi^{-1} \sin \theta\left\langle\left|H_{T}\right|^{2}\right\rangle$

499

and

500

$Q_{3}^{\prime}=\left[1+f^{2} r^{2} \xi^{-2}+2 f r \xi^{-1} \cos \theta\right]\left\langle\left|H_{T}\right|^{2}\right\rangle$ 
502 A final observation made by Kirby \& Swain (2009), made on synthetic data, was that

503 correlated initial loads had the property $\langle\cos \theta\rangle \approx 1$, while randomly correlated loads had

$504\langle\cos \theta\rangle \approx 0$, implying that the correlated loading regime is characterised by $\theta=0^{\circ}$ and the

505 randomly-correlated regime by $\theta=90^{\circ}$ (see also Wieczorek (2007)). Since in this study the

506 synthetic loads are all randomly correlated we can use $\cos \theta=0$ and $\sin \theta=1$ in eqs (20) -

507 (22), which makes eq. (15) become

508

$Q_{T B}{ }^{\prime}=\frac{\left(Q_{T}+Q_{B} f^{2} r^{2} \xi^{-2}\right)\left\langle\left|H_{T}\right|^{2}\right\rangle+i\left(Q_{T}-Q_{B}\right) f r \xi^{-1}\left\langle\left|H_{T}\right|^{2}\right\rangle}{\left(1+f^{2} r^{2} \xi^{-2}\right)\left\langle\left|H_{T}\right|^{2}\right\rangle}$

509 Cancelling the $\left\langle\left|H_{T}\right|^{2}\right\rangle$ terms, and using eqs (7) and (8), the analytic expression can be

510 written as

511

$Q_{T B}{ }^{\prime}(k)=-2 \pi \mathcal{G} \Delta \rho_{0} e^{-k z}\left(\frac{\xi+\phi f^{2} r^{2}+i f r(1-\phi \xi)}{\xi^{2}+f^{2} r^{2}}\right)$

512 Note how the real part of eq. (24) is identical to eq. (9), the (real) combined-loading

513 admittance.

514

515

The (complex) 2-D observed admittance of the synthetic models was computed in

wavenumber space using eq. (12) and using Slepian multitapers (see Fig. 3 caption). Rather

than plotting the 2-D observed admittance estimates as a function of $\mathbf{k}=\left(k_{x}, k_{y}\right)$, they were

plotted (without averaging around annuli) on 1-D graphs as functions of their radial

519

wavenumber $k=|\mathbf{k}|$ as green dots in Fig. 3. The blue curves in Fig. 3 show the real and

imaginary theoretical admittance functions from eq. (24).

522 Figs 3(a) and (b) show that when the synthetic Bouguer anomaly and topography were generated from a plate with $T_{e}=0 \mathrm{~km}$ (Airy isostasy, implying $F=0$ ) the real and imaginary 
observed admittance estimates agreed very well with the theoretical curves. When they were generated from surface-loading only $(F=0)$ on a plate of $T_{e}=40 \mathrm{~km}$, there was also good agreement (Figs 3c and d). Note how the observed imaginary parts in Figs 3(b) and (d) are almost uniformly zero at all wavelengths, agreeing with the theoretical predictions of eq. (24) when $f=F=0$.

When the synthetic Bouguer anomaly and topography were generated from combined loading $(F=0.5)$ of a plate with $T_{e}=40 \mathrm{~km}$, the real observed admittance estimates show a certain degree of scatter about the theoretical curve (Fig. 3e), particularly at medium to short wavelengths, which is expected and arises from random correlations between the two synthetic loads (Kirby \& Swain 2008). In contrast to the Airy and surface loading models, the observed admittance in the combined loading case gains a non-zero imaginary part (Fig. 3f), in agreement with eqs (14) and (24) because there are now two independent processes in action. But it can be seen that the imaginary observed admittance estimates in Fig. 3(f) do not follow the imaginary theoretical admittance curve; they cluster about the zero-admittance axis, rather than the theoretical imaginary curve. [Interestingly, there are no estimates that lie outside the curve (and its negative reflection about the axis), so it could be said that the theoretical curve provides an envelope within which all observed imaginary admittance estimates fall.]

This mismatch between the observed and theoretical imaginary admittance provides the answer to the problem raised above: why is the isostatic anomaly for combined loading nonzero (Fig. 1c), when the loading model is known exactly? First note that with any type of noise-free synthetic flexure model, in order to retrieve zero isostatic anomalies the compensation attraction must be perfectly recovered from a formula of the type 
$\delta g_{C}=\mathbf{F}^{-1}\left[Q_{t h} H\right]$, and for this the admittance $Q$ needs to be an accurate representation of the

550

551

552 actual synthetic model plate filter, where, given initial loads the plate filter produces a gravity anomaly and topography. Whether this filter is manifested as flexural equations or as admittances is unimportant. Indeed, if the observed (complex) admittance, $Q_{o b s}$, was computed from the synthetic Bouguer anomaly and topography through eq. (12) and then a compensation attraction retrieved via $\delta g_{C}=\mathbf{F}^{-1}\left[Q_{o b s} H\right]$, the synthetic Bouguer anomaly and retrieved compensation attraction would be almost identical (but not exactly due to multitaper averaging when computing the admittance). This would apply to real-Earth data too, except here $Q_{o b s}$ would contain much more than just isostatic information.

Consequently, in the surface-only loading model the real theoretical admittance curves are a very good fit to the real observed admittance estimates (Fig. 3c), so that when the theoretical admittance function, eq. (7), is used with the topography Fourier transform in eq. (11), or $\delta g_{C}=\mathbf{F}^{-1}\left[Q_{T} H\right]$, the retrieved compensation attraction exactly reproduces the actual Bouguer anomaly. That is, performing $\mathbf{F}^{-1}\left[Q_{T} H\right]$ with a theoretical admittance gives almost the same results as performing $\mathbf{F}^{-1}\left[Q_{o b s} H\right]$ with an observed admittance; both yield a compensation attraction that exactly matches the Bouguer anomaly (for these noise-free, surface-loading synthetic models). The same is true for the Airy isostatic case.

In the combined-loading models the compensation attraction is also obtained using a realvalued theoretical analytic admittance, $\delta g_{C}=\mathbf{F}^{-1}\left[Q_{T B} H\right]$ with $Q_{T B}$ given by eq. (9). But even though $Q_{T B}$ is a fair fit to the real, observed admittance (Fig. 3e), use of a real-valued analytic admittance will always yield antiphase $\left(180^{\circ}\right)$ compensation attraction and topography when in fact the combined model synthetic Bouguer anomaly and topography actually have random 
phase due to the independence of the initial surface and subsurface loads. This means that the difference $\Delta g_{B}-\delta g_{C}$ will not account for the out-of-phase harmonics between $\Delta g_{B}$ and $h$, and will be non-zero. Since $\Delta g_{B}-\delta g_{C}$ is interpreted as the isostatic anomaly (eq. (1)), it appears that there exists a non-zero isostatic anomaly even in this noise-free example. The conclusion is that the compensation model has failed, even if $T_{e}, F$, densities and depths have actually been estimated accurately.

And unfortunately the situation cannot be remedied by use of a complex analytic admittance, which would at least generate out-of-phase gravity and topography; for example, using $Q_{T B}{ }^{\prime}$ from eq. (24) to generate the compensation attraction from $\delta g_{C}=\mathbf{F}^{-1}\left[Q_{T B}{ }^{\prime} H\right]$. While the real part of $Q_{T B}{ }^{\prime}$ is a fair fit to the real, observed admittance (Fig. 3e), its imaginary part is definitely not (Fig. 3f), so $\mathbf{F}^{-1}\left[Q_{T B}{ }^{\prime} H\right]$ will not yield anything remotely resembling the compensation attraction. Therefore, while useful in providing a theoretical understanding of phase relationships between gravity and topography, complex analytic admittance formulae such as eq. (24) have little practical value. This is most likely due to the assumptions made regarding the phase difference $\theta$ when deriving eq. (24).

In summary, if both surface and subsurface loading are present, then the correct compensation and isostatic anomalies cannot be estimated using spectral methods. Complex analytic admittance functions do not faithfully represent the imaginary admittance, while real analytic admittance functions cannot correctly predict the phase difference between gravity and topography. 


\subsection{Tests of varying compensation depth}

597 This experiment sought to ascertain the error in estimating compensation depth, when an Airy

598

599

600

601

602

603

604

605

606

607

608

609

610

611

612

613

614

615

616

617

618

619

isostatic model is used to interpret gravity and topography data generated from a plate with $T_{e}$

$>0 \mathrm{~km}$. As described in Section 3.2, 10,100 synthetic Bouguer anomaly and topography pairs were generated from combined loading on plates with $T_{e}$ ranging from 0 to $100 \mathrm{~km}$, in steps of $1 \mathrm{~km}$ (101 values), and $F$ ranging from 0 to 0.99 , in steps of 0.01 (100 values).

Lithospheric parameters were set as: crust density $2800 \mathrm{~kg} \mathrm{~m}^{-3}$, crust thickness (and compensation depth) $35 \mathrm{~km}$, mantle density $3300 \mathrm{~kg} \mathrm{~m}^{-3}$, as usual. The compensation attraction was then recovered from the topography using the Airy admittance function, eq. (5) , 196 times, using depth to compensation values $\left(z_{m}\right)$ ranging from 5 to $200 \mathrm{~km}$, in steps of 1 $\mathrm{km}$. From each of the $1,979,600(=101 \times 100 \times 196)$ compensation attractions the corresponding isostatic anomaly was computed using eq. (4), and its normalized standard deviation $\left(\bar{\sigma}_{I A}\right)$ calculated (an example for $F=0$ is shown in Fig. 4 a). For each model with a certain $\left(F, T_{e}\right)$ value, the value of $z_{m}$ that gave the smallest $\bar{\sigma}_{I A}$ was determined, and plotted in Fig. 4(b).

Both plots in Fig. 4 show how compensation depth can be overestimated if an Airy model is assumed, when loading is surface-only. For example, consider a region of the Earth where the actual, but unknown, $T_{e}$ is $40 \mathrm{~km}$, and one wishes to find the compensation depth when erroneously assuming that $T_{e}=0 \mathrm{~km}$. If one used a method to find the compensation depth such as that presented here, i.e. by finding that compensation depth over a range of values that minimized the isostatic anomaly standard deviation, one would retrieve $z_{m} \approx 110 \mathrm{~km}$ from Figs 4(a) and (b), a value greater than its true value by $75 \mathrm{~km}$. For combined-loading scenarios $(F>0)$, Fig. 4(a) no longer applies and one must turn to Fig. 4(b). Now, if the 
actual $T_{e}$ were $40 \mathrm{~km}$ but the internal load fraction $F=0.5$, then the estimated compensation depth would be approximately $50 \mathrm{~km}$.

Fig. 4(b) shows that the largest overestimates of the actual compensation depth occur when the initial loading is predominantly at the surface $(F<0.5)$, and then when $T_{e}$ is high. Furthermore, large underestimates of compensation depth occur when there exist significant subsurface loads $(F>0.8)$ in a plate of high $T_{e}$. Indeed, compensation depth is only recovered accurately in a very narrow range of $\left(F, T_{e}\right)$ values, $T_{e}<5 \mathrm{~km}$, or $0.65<F<0.7$, approximately, as shown by the red contours in Fig. 4(b).

\section{DISCUSSION}

\subsection{Subsurface loading}

Studies have shown that that subsurface loading exists in many regions worldwide, and that it plays a key role in flexure and in the compensation of surface loads (e.g. Karner \& Watts 1983). However, it has been shown in Section 3.2.4 that combined surface and subsurface loading cannot be realistically accounted for in the determination of isostatic anomalies. This is because the admittance, when multiplied by the observed surface topography, does not accurately model the compensation at the surface of subsurface loads generated during combined loading and flexure of a plate of $T_{e}>0 \mathrm{~km}$. Since subsurface loading, and its effect upon the surface topography and gravity field, is part of the flexural-isostatic process, the question of whether an isostatic anomaly is meaningful must be raised.

The detrimental effect of subsurface loads upon isostatic anomaly estimation is not unknown. Such loads can be emplaced or generated during many tectonic events such as the obduction of oceanic crust, the development of accretionary wedges and the mobilization of thrust 
sheets and nappes during continental convergence, emplacement of subsurface plutons during volcanic activity, intra-crustal thrusts, and dense downgoing slabs (e.g. Karner \& Watts 1983; Forsyth 1985; Jordan \& Watts 2005). They may be shallow, such as crustal blocks of different compositions, sedimentary basins, or igneous intrusions, or deep, such as density anomalies due to crustal underplating, lithospheric thermal anomalies or deeper compositional variations (Zuber et al. 1989). Most importantly, they are often expressed in the Bouguer anomaly but not in the topography, leading to incorrect Airy isostatic anomalies which are derived under the assumption that the topography is the only load acting on the lithosphere (e.g. Watts \& Talwani 1974; McNutt 1980; Karner \& Watts 1983; Forsyth 1985). For example, in their study of isostasy at orogenic belts, Karner \& Watts (1983) showed that the maximum crustal thickness in the Alps does not occur under the highest elevations as Airy isostasy would predict, but rather under the large subsurface loads that characterise the Ivrea zone. The rigidity of the lithosphere here prevents hydrostatic adjustment of the subsurface density anomalies, but isostatic balance is still maintained.

The difficulty, if not impossibility, of accounting for subsurface loads when estimating isostatic anomalies using transfer function (admittance) methods has been acknowledged qualitatively by several authors (e.g. McNutt 1980; Ussami et al. 1993; Watts et al. 1995; Harmon et al. 2006). This study has quantified and confirmed that. However, subsurface loads can be included in an isostatic anomaly if the computation of their gravity effect is performed in the space domain, as Karner \& Watts (1983) did. Space domain modelling is, however, comparatively tedious compared with admittance methods in that it involves forward modelling the subsurface density distributions, perhaps constrained by independent (e.g. seismic) data, and adjusting $T_{e}$ to match the observed gravity field. 
670 One possible approach would be to acknowledge but ignore subsurface loads, and use

671 surface-loading models only (e.g. Ussami et al. 1993; Watts \& Moore 2017). And this might

672 be considered appropriate, given that the tests conducted in this paper have shown that the

673 real-valued combined loading admittance function, eq. (9), does not give correct isostatic

674 anomalies even when $T_{e}, F$ and the compensation depth are known (test C, Fig. 1c).

675 However, the tests have also shown that the assumption of only surface loading when both

676 surface and subsurface loads are present can, in certain scenarios, yield larger isostatic

677 anomalies than when Airy isostasy is assumed (compare Figs 1a and b). It is worth noting

678 though that accurate knowledge of $T_{e}, F$ and compensation depth (test C, Fig. 1c) does yield

679 smaller average isostatic anomalies than when these parameters are unknown, even though

680 the spatial distribution of computed isostatic anomalies may not reflect their actual

681 distribution.

682

\section{$683 \quad 4.2$ Coherence transition wavelength}

684 The assumption of local isostatic compensation underestimates the ability of the lithosphere 685 to mechanically support topographic loads, resulting in an overestimation of the depth to 686 compensation, as noted in Section 1, and demonstrated in Section 3.3. In many studies it is often assumed that most surface topographic loads are isostatically compensated, or at least that mechanically supported loads are of such a small wavelength as to be irrelevant to that study's conclusions (e.g. Kaban et al. 1999, 2004). Often, this 'transition' wavelength (from compensated to supported topography) is assumed to be uniform across the study area, with an arbitrarily chosen value (e.g. Martinec 1994b; Kaban et al. 2004; Bagherbandi et al. $T_{e}$ and initial loading ratio $(f)$. 
One possible method to separate compensated from supported topography is to analyse the wavenumber-domain coherence between Bouguer anomalies $(G)$ and topography $(H)$ :

$$
\gamma^{2}(k)=\frac{\left|\left\langle G(\mathbf{k}) H(\mathbf{k})^{*}\right\rangle\right|^{2}}{\left\langle G(\mathbf{k}) G(\mathbf{k})^{*}\right\rangle\left\langle H(\mathbf{k}) H(\mathbf{k})^{*}\right\rangle}
$$

(e.g. Forsyth 1985). The Bouguer coherence will have values close to zero at short wavelengths because such small loads can be adequately supported by the mechanical strength of the plate (Fig. 5): small surface loads retain a topographic signature but do not generate a Bouguer anomaly because the compensating interface (e.g. the Moho) does not flex; small subsurface loads generate a Bouguer anomaly but do not produce a surface topography by flexure. At the other end of the spectrum, long wavelength loads cannot be mechanically supported, and the loads (both surface and subsurface) are hydrostatically compensated; the Bouguer coherence is hence unity. There is, then, a transition wavelength $\left(\lambda_{\mathrm{T}}\right)$, at which the Bouguer anomaly and topography transition from being incoherent (with wavelength $\left.\lambda<\lambda_{\mathrm{T}}\right)$ to coherent $\left(\lambda>\lambda_{\mathrm{T}}\right)$, which can also be interpreted as the wavelength at which the loads transition from being supported to compensated.

By way of example, Fig. 6(b) shows a map of the value of the predicted Bouguer coherence transition wavelength over Europe and surrounding seas, where $\lambda_{\mathrm{T}}$ is taken to be the wavelength at which the coherence has a value of 0.5 . The predicted coherence was estimated by application of the fan-wavelet adaptation of Forsyth's (1985) method (Kirby \& Swain 2008) to EGM2008 gravity data (Pavlis et al. 2012), rock-equivalent topography from the Earth2014 model (Hirt \& Rexer 2015), and the depths and densities of the CRUST1.0 model (Laske et al. 2013). The resulting $T_{e}$ map (Fig. 6a) broadly agrees with the estimate obtained by Pérez-Gussinyé \& Watts (2005) using the multitaper method, and is not discussed here. 
719 Note that the map in Fig. 6(b) shows the transition wavelength of both (post-flexure) surface and subsurface loads, because the predicted coherence (and hence $\lambda_{\mathrm{T}}$ ) is computed by Forsyth's (1985) method that assumes that both types of load are present. Fig. 6(b) shows that the transition wavelength from compensated to supported topography is highly variable, with the weaker lithosphere of western and southern Europe much less able to mechanically support large loads than the stronger eastern European and Asian lithosphere. The lithosphere in western and southern Europe is able to support loads with wavelengths $<400 \mathrm{~km}$ approximately, while the stronger lithosphere to the east can adequately support loads with wavelengths up to $\sim 1200 \mathrm{~km}$.

\subsection{Implications for dynamic topography studies}

Under the reasoning that the Earth's actual topography is the sum of isostatic and dynamic components, models of isostatic compensation are frequently used to isolate dynamic topography (e.g. Forte et al. 1993; Perry et al. 2002; Boschi et al. 2010; Komut et al. 2012; Bagherbandi et al. 2015). To date Airy isostasy has been the model of choice. Assuming Airy isostasy, the undulations of a seismically-determined Moho can be used to predict the isostatic topography that the Moho undulations compensate, as shown below.

Consider an incompressible crust of uniform density $\rho_{c}$ overlying an inviscid mantle of greater uniform density $\rho_{m}$, and itself overlain by a fluid of lesser density $\rho_{f}$, either air or water. An applied surface load also of density $\rho_{c}$ then deflects the crust resulting in surface topography $h(x)$ and Moho relief of $w(x)$. Under Airy isostatic compensation, the pressure generated from displacement of the fluid by the surface topography must balance the pressure

742 generated by displacement of the mantle by the Moho, thus 
744 where $g$ is the gravity acceleration, $\Delta \rho_{0}=\rho_{c}-\rho_{f}$ and $\Delta \rho_{1}=\rho_{m}-\rho_{c}$, giving

$745 \quad w(x)=-\frac{\Delta \rho_{0}}{\Delta \rho_{1}} h(x)$

746 This is the Airy isostatic case, and it is instructive to work in the wavenumber domain by

747 taking the Fourier transform of eq. (27):

748

$H(k)=-\frac{\Delta \rho_{1}}{\Delta \rho_{0}} W(k)$

749

750

751

752

753

754

755

756

757

758

759

760

761

762

763

764

765

766

where capital letters indicate the function's Fourier transform. For example, $1 \mathrm{~km}$ of Moho relief $(W)$ compensates $0.179 \mathrm{~km}$ of subaerial surface topography $(H)$, at any wavelength of relief anomaly (using density values from Table 1).

$W(k)$ can be obtained from a seismic Moho model, then eq. (28) used to find $H(k)$ the derived isostatic topography. Then, the difference between the actual, observed topography (from a DEM for example) and the isostatic topography is interpreted as the dynamic topography. Different authors have attributed different phenomena to explain the dynamic processes that support the topography (e.g. Molnar et al. 2015), and it is not the purpose of this paper to comment on those. However, as Molnar et al. (2015) point out, the error on most seismic models of the Moho is at least $2 \mathrm{~km}$ and often more than $5 \mathrm{~km}$, which by eq. (28) imparts an error of at least $0.4-0.9 \mathrm{~km}$ on the isostatic, and thus dynamic, topography when derived in this manner. This error, they say, is often greater than the estimate.

Another source of error arises from the omission of plate rigidity in solutions. The contribution of flexural rigidity to such studies of dynamic topography can be estimated by considering the amount of surface topography that is compensated or supported by a specified Moho relief anomaly, in an extension of the Airy isostasy case discussed above. 
767

768

769

770

771

772

773

774

775

776

777

778

779

780

781

782

783

784

785

786

787

788

789

When the plate possesses non-zero rigidity, two processes must be considered. The first process, surface loading, asks 'when an initial surface load applied to a plate generates a

Moho relief anomaly of amplitude $1 \mathrm{~km}$ after flexure, what is the amplitude of the postflexural surface topography?' The solution is obtained in a similar manner to the Airy case, above, but now the forces produced by the load are laterally distributed, and a fourth-order derivative term representing the bending stress (e.g. Watts, 2001) must be introduced into eq. (26):

$-\Delta \rho_{0} g h_{T}(x)=\Delta \rho_{1} g w_{T}(x)+D \frac{\partial^{4} w_{T}(x)}{\partial x^{4}}$

Now using the subscript ' $\mathrm{T}$ ' to denote surface loading, if $D$ is spatially uniform, eq. (29) can be solved by taking its Fourier transform:

$-\Delta \rho_{0} g H_{T}(k)=\Delta \rho_{1} g W_{T}(k)+D k^{4} W_{T}(k)$

or:

$H_{T}(k)=\frac{-\left(D k^{4}+\Delta \rho_{1} g\right)}{\Delta \rho_{0} g} W_{T}(k)$

Eq. (31) is plotted in Fig. 7(a) for several values of $T_{e}$, as a function of load wavelength $\left(\lambda^{\prime}=\right.$ $\left.2 \pi / k^{\prime}\right)$ where the load in this case is a delta function in the Fourier domain with value $-1 \mathrm{~km}$ at wavenumber $k^{\prime}$ and zero elsewhere (i.e. a sinusoid in the space domain), or $W_{T}(k)=-\delta(k-$ $\left.k^{\prime}\right)$. Under Airy isostasy $(D=0), W_{T}=-1 \mathrm{~km}$ of Moho relief compensates $H_{T}=0.179 \mathrm{~km}$ of surface topography, for any wavelength of Moho relief and surface topographic expression, as noted above. However, as load wavelength decreases and/or $T_{e}$ increases, it becomes harder and harder to flex the plate sufficiently to produce $1 \mathrm{~km}$ of Moho relief. For example, under initial surface loading, in order to compensate a $500 \mathrm{~km}$-wavelength Moho relief anomaly of amplitude $-1 \mathrm{~km}$ on a plate with $T_{e}=80 \mathrm{~km}$, a surface load of amplitude 4.319 
$\mathrm{km}$ is required, or $4.14 \mathrm{~km}$ more than expected for Airy isostasy. Thus, if an Airy model is used to separate the isostatic from dynamic topography, then the isostatic topography may be underestimated and the dynamic topography therefore overestimated.

The second process, subsurface loading, asks 'when a subsurface load applied to a plate generates a Moho relief anomaly of amplitude $1 \mathrm{~km}$ after flexure, what is the amplitude of the post-flexural surface topography?' The subsurface loading analogue of eq. (30) is

$$
-\Delta \rho_{1} g W_{B}(k)=\Delta \rho_{0} g H_{B}(k)+D k^{4} H_{B}(k)
$$

(e.g. Forsyth 1985) which becomes

$$
H_{B}(k)=\frac{-\Delta \rho_{1} g}{D k^{4}+\Delta \rho_{0} g} W_{B}(k)
$$

Eq. (33) is plotted in Fig. 7(b) for several values of $T_{e}$, where $W_{B}(k)=-\delta\left(k-k^{\prime}\right)$. Under Airy isostasy $(D=0), W_{B}=-1 \mathrm{~km}$ of Moho relief compensates $H_{B}=0.179 \mathrm{~km}$ of surface topography, for any wavelength of Moho relief and surface topographic expression, as for the surface loading case, above. However, as load wavelength decreases and/or $T_{e}$ increases, the surface topographic amplitude decreases to zero. For example, under initial subsurface loading, a $500 \mathrm{~km}$-wavelength Moho relief anomaly of amplitude $1 \mathrm{~km}$ on a plate with $T_{e}=$ $80 \mathrm{~km}$ compensates a surface load of amplitude $0.035 \mathrm{~km}$, or $0.144 \mathrm{~km}$ less than expected for Airy isostasy. Thus, if an Airy model is used to separate the isostatic from dynamic topography, then the isostatic topography may be overestimated and the dynamic topography therefore underestimated. Note that it is difficult to combine the expressions for surface and subsurface loading due to the likely phase difference between the two processes.

Hence it can be seen that determination of the isostatic topography, let alone dynamic topography, is difficult. In addition to dealing with the error in Moho depth, one has to decide 
whether surface or subsurface loading dominated the region, and be confident in that decision because, as seen, the two can have very different results. While one could use the loading ratio, $f$, provided by Forsyth's (1985) coherence method to estimate the relative amounts of each loading type at different wavelengths, one would also have to recreate the initial loads in order to ascertain the phase difference between them. Fortunately, recreating initial loads is achievable via Forsyth's (1985) method (e.g. Bechtel et al. 1987), and Lowry et al. (2000) have used such an approach when computing dynamic topography in the U.S. Cordillera.

Many studies write that they avoid the effect of flexural rigidity by low-pass frequency filtering the data in order to operate in harmonics where loads are hydrostatically compensated rather than mechanically supported (e.g. Forte et al. 1993; Perry et al. 2002; Boschi et al. 2010; Komut et al. 2012; Bagherbandi et al. 2015). This supposition is correct and can be seen in Fig. 7. For a given $T_{e}$ value, the wavelength at which the $H_{T}(k)$ or $H_{B}(k)$ curve intersects the Airy $\left(T_{e}=0\right)$ line provides the minimum wavelength at which a dynamic topography study will be free from the effects of flexural rigidity. For example, if $T_{e}=80 \mathrm{~km}$ then low-pass filtering the observed topography and Moho relief with a cut-off of $2000 \mathrm{~km}$ (spherical harmonic degree $<20$ ) will ensure that only Airy compensation signals are present in the data. If $T_{e}$ is lower, $10 \mathrm{~km}$ say, then the cut-off only need be $500 \mathrm{~km}$ (spherical harmonic degree $<80$ ).

But as discussed in Section 4.2 the cut-off wavelength in the above-cited studies often seems to be arbitrarily chosen, and sometimes is not chosen per se at all, but rather is implied by the resolution of the Moho depth model (e.g. Perry et al. 2002; Boschi et al. 2010; Komut et al. 2012). Many studies overcompensate and select cut-off wavelengths far in excess of the minimum needed (e.g. Forte et al. 1993; Bagherbandi et al. 2015). Three exceptions who 
have taken elastic thickness into account when choosing cut-off wavelengths are Kaban et al. (2004) and Braun et al. (2014), albeit differently to here, and Watts \& Moore (2017) though their study is of global average spectra.

\section{CONCLUSIONS}

It has been shown here that attempts to determine mechanisms of isostatic compensation of surface topographic features, and thence isostatic gravity anomalies, are prone to failure for several reasons. First, many attempts omit, by accident or design, flexural rigidity from computations. As with any inversion method, omission of an important inversion parameter will affect the values of those remaining parameters chosen for estimation, for example, the depth to compensating interface. Experiments with synthetic models have shown that the flexural rigidity, or its geometric analogue the effective elastic thickness, is indeed an important parameter in isostatic compensation and its omission can affect isostatic anomaly standard deviations by up to 214 per cent of the corresponding Bouguer anomaly standard deviation, for the models considered here. To address these shortcomings, it is recommended that (1) elastic thickness be included, if possible, in isostatic anomaly modelling, and (2) that isostatic anomaly power spectra, rather than standard deviations, relative to the Bouguer anomaly be analysed. The second recommendation is important because isostatic anomalies may have a low standard deviation but still have high power at short wavelengths relative to the Bouguer anomaly. This happens because of the redness of the Earth's gravity and topography spectra: for example, a power difference of $10^{3}$ between Bouguer and isostatic anomalies at long wavelengths contributes much more to the whole-spectrum average power than does a $10^{3}$ power difference at short wavelengths. 
Equally as important as elastic thickness is the role of subsurface loads. Such loads are isostatically compensated and manifested in the present-day topography. If they are present yet ignored and the topography is assumed to comprise only surface loads, then inversion of the topography for isostatic model parameters will, again, yield incorrect parameter estimates. But most importantly, transfer function (admittance) methods cannot properly account for subsurface loads when they coexist with surface loads. This is true even if complex-valued analytic transfer functions are employed that should, in theory, account for phase differences between the two loads, but in practice do not. This suggests that more ingenious methods must be devised in order to obtain more realistic isostatic anomalies.

Isostatic anomalies can also be inverted for the depth to the compensating density interface, often assumed to be the Moho. Again, if $T_{e}$ is ignored and an Airy isostatic model assumed, then the Moho depth estimate will always be larger than the reality. This further affects derived values of the dynamic topography when Moho depths are used for its estimation. Coupled with an uncertainty of the role of subsurface loading, omission of $T_{e}$ from analyses can lead to very large overestimates, or moderate underestimates of the dynamic topography. In addition to dynamic support, $T_{e}$ plays a strong role in the mechanical support of topography. The size of topographic load that can be supported by a plate, as opposed to hydrostatically compensated, can be found by estimation of the Bouguer coherence transition wavelength.

Given the noted shortcomings of local isostatic models, one must question their continued use. If $T_{e}$ and the degree of subsurface loading can be reliably estimated in a region then derived isostatic anomalies will have slightly lower power than those obtained under the assumption of Airy isostasy, especially for high values of $T_{e}$ and predominantly surface 
loading (compare Figs 1a and b, 2a and b). However, as no transfer function-based method can ever model the gravitational attraction of the compensation with $100 \%$ accuracy (for $T_{e}$ and $F>0$ ), non-zero isostatic anomalies will always be observed, and potentially misinterpreted.

\section{ACKNOWLEDGEMENTS}

I would like to thank the reviewers, Tony Lowry and two anonymous, whose comments greatly improved this manuscript.

\section{REFERENCES}

Abd-Elmotaal, H., 1993. Vening Meinesz Moho depths: traditional, exact and approximated, Manuscr. Geod., 18, 171-181.

Airy, G.B., 1855. On the computations of the effect of the attraction of the mountain-masses, as disturbing the apparent astronomical latitude of stations in geodetic surveys, Phil. Trans. R. Soc. Lond., 145, 101-104.

Aitken, A.R.A., Altinay, C. \& Gross, L., 2015. Australia's lithospheric density field, and its isostatic equilibration, Geophys. J. Int., 203, 1961-1976.

Bagherbandi, M. \& Sjöberg, L.E., 2012. Non-isostatic effects on crustal thickness: a study using CRUST2.0 in Fennoscandia, Phys. Earth planet. Inter., 200-201, 37-44.

Bagherbandi, M., Tenzer, R., Sjöberg, L.E. \& Abrehdary, M., 2015. On the residual isostatic topography effect in the gravimetric Moho determination, J. Geodyn., 83, 28-36.

Balmino, G., Vales, N., Bonvalot, S. \& Briais, A., 2012. Spherical harmonic modelling to ultra-high degree of Bouguer and isostatic anomalies, J. Geod., 86, 499-520.

Banks, R.J., Parker, R.L. \& Huestis, S.P., 1977. Isostatic compensation on a continental scale: local versus regional mechanisms, Geophys. J. R. astr. Soc., 51, 431-452. 
Bechtel, T.D., Forsyth, D.W. \& Swain, C.J., 1987. Mechanisms of isostatic compensation in the vicinity of the East African Rift, Kenya, Geophys. J. R. astr. Soc., 90. 445-465.

Boschi, L., Faccenna, C. \& Becker, T.W., 2010. Mantle structure and dynamic topography in the Mediterranean Basin, Geophys. Res. Lett., 37, L20303, doi:10.1029/2010GL045001.

Braun, J., Simon-Labric, T., Murray, K.E. \& Reiners, P.W., 2014. Topographic relief driven by variations in surface rock density, Nat. Geosci., 7, 534-540.

Brotchie, J.F. \& Silvester, R., 1969. On crustal flexure, J. geophys. Res., 74, 5240-5252.

Burov, E.B. \& Diament, M., 1995. The effective elastic thickness $\left(T_{e}\right)$ of continental lithosphere: what does it really mean? J. geophys. Res., 100(B3), 3905-3927.

Cordell, L., Zorin, Y.A. \& Keller, G.R., 1991. A decompensative gravity anomaly and deep structure of the region of the Rio Grande rift, J. geophys. Res., 96(B4), 6557-6568.

Dorman, L.M. \& Lewis, B.T.R., 1970. Experimental isostasy: 1. Theory of the determination of the Earth's isostatic response to a concentrated load, J. geophys. Res., 75, 3357-3365.

Dorman, L.M. \& Lewis, B.T.R., 1972. Experimental isostasy: 3. Inversion of the isostatic Green function and lateral density changes, J. geophys. Res., 77, 3068-3077.

England, P. \& Molnar, P., 2015. Rheology of the lithosphere beneath the central and western Tien Shan, J. geophys. Res., 120, 3803-3823.

Eshagh, M., 2016. A theoretical discussion on Vening Meinesz-Moritz inverse problem of isostasy, Geophys. J. Int., 207, 1420-1431.

Eshagh, M., 2018. Elastic thickness determination based on Vening Meinesz-Moritz and flexural theories of isostasy, Geophys. J. Int., 213, 1682-1692.

Forsyth, D.W., 1985. Subsurface loading and estimates of the flexural rigidity of continental lithosphere, J. geophys. Res., 90(B14), 12,623-12,632. 
936 Forte, A.M., Peltier, W.R., Dziewonski, A.M. \& Woodward, R.L., 1993. Dynamic surface

937 topography: a new interpretation based upon mantle flow models derived from seismic 938 tomography, Geophys. Res. Lett., 20, 225-228.

939 Harmon, N., Forsyth, D.W. \& Scheirer, D.S., 2006. Analysis of gravity and topography in the 940 GLIMPSE study region: isostatic compensation and uplift of the Sojourn and Hotu Matua 941 Ridge systems, J. geophys. Res., 111, B11406, doi:10.1029/2005JB004071.

942 Hayford, J.F., 1909. The Figure of the Earth and Isostasy from Measurements in the United $943 \quad$ States, pp 178, Government Printing Office.

944 Heiskanen, W.A., 1931. Isostatic tables for the reduction of gravimetric observations 945 calculated on the basis of Airy's hypothesis, Bull. Géod., 30, 110-153.

946 Heiskanen, W.A. \& H. Moritz, 1967. Physical Geodesy, W.H. Freeman.

947 Hirt, C. \& Rexer, M., 2015. Earth2014: 1 arc-min shape, topography, bedrock and ice-sheet 948 models - available as gridded data and degree-10,800 spherical harmonics, Int. J. Appl. 949 Earth Observation Geoinformation, 39, 103-112.

950 Hirt, C., Kuhn, M., Featherstone, W.E. \& Göttl, F., 2012. Topographic/isostatic evaluation of 951 new-generation GOCE gravity field models, J. geophys. Res., 117, B05407, doi: 10.1029/2011JB008878.

Ito, G. \& Taira, A., 2000. Compensation of the Ontong Java Plateau by surface and 954 subsurface loading, J. geophys. Res., 105(B5), 11,171-11,183. Jordan, T.A. \& Watts, A.B., 2005. Gravity anomalies, flexure and the elastic thickness structure of the India-Eurasia collisional system, Earth planet. Sci. Lett., 236, 732-750.

957 Kaban, M.K., Schwintzer, P. \& Tikhotsky, S.A., 1999. A global isostatic gravity model of the 958 Earth, Geophys. J. Int., 136, 519-536.

959 Kaban, M.K., Schwintzer, P. \& Reigber, C., 2004. A new isostatic model of the lithosphere 960 and gravity field, J. Geod., 78, 368-385. 
961 Karner, G.D. \& Watts, A.B., 1982. On isostasy at Atlantic-type continental margins, $J$. 962 geophys. Res., 87(B4), 2923-2948.

963 Karner, G.D. \& Watts, A.B., 1983. Gravity anomalies and flexure of the lithosphere at 964 mountain ranges, J. geophys. Res., 88(B12), 10,449-10,477.

965 Kaula, W.M., 1967. Geophysical implications of satellite determinations of the Earth's 966 gravitational field, Space Sci. Rev., 7, 769-794.

967 Kirby, J.F., 2014. Estimation of the effective elastic thickness of the lithosphere using inverse 968 spectral methods: the state of the art, Tectonophysics, 631, 87-116.

969 Kirby, J.F. \& Swain, C.J., 2008. An accuracy assessment of the fan wavelet coherence 970 method for elastic thickness estimation, Geochem. Geophys. Geosyst., 9, Q03022, 971 doi:10.1029/2007GC001773.

972 Kirby, J.F. \& Swain, C.J., 2009. A reassessment of spectral $T_{e}$ estimation in continental 973 interiors: the case of North America, J. geophys. Res., 114(B8), B08401, 974 doi:10.1029/2009JB006356.

975 Kirby, J.F. \& Swain, C.J., 2013. Power spectral estimates using two-dimensional Morlet-fan 976 wavelets with emphasis on the long wavelengths: jackknife errors, bandwidth resolution and 977 orthogonality properties, Geophys. J. Int., 194, 78-99.

978 Komut, T., Gray, R., Pysklywec, R. \& Göğüş, O.H., 2012. Mantle flow uplift of western 979 Anatolia and the Aegean: interpretations from geophysical analyses and geodynamic 980 modelling, J. geophys. Res., 117, B11412, doi:10.1029/2012JB009306.

981 Kuhn, M., 2003. Geoid determination with density hypotheses from isostatic models and 982 geological information, J. Geod., 77, 50-65.

983 Lachapelle, G., 1976. A spherical harmonic expansion of the isostatic reduction potential, 984 Bollettino di Geodesia e Scienze Affini, 3, 281-299. 
985

986

987

988

989

990

991

992

993

994

995

996

997

998

999

1000

1001

1002

1003

1004

1005

1006

1007

1008

Laske, G., Masters, G., Ma, Z. \& Pasyanos, M., 2013. Update on CRUST1.0 - a 1-degree global model of Earth's crust, in Geophysical Research Abstracts. Vol. 15, Eur. Geosci. Un., Munich, p. EGU2013-2658.

Lewis, B.T.R. \& Dorman, L.M., 1970. Experimental isostasy, 2: An isostatic model for the USA derived from gravity and topography data, J. geophys. Res., 75, 3367-3386.

Louden, K.E. \& Forsyth, D.W., 1982. Crustal structure and isostatic compensation near the Kane fracture zone from topography and gravity measurements: 1. Spectral analysis approach, Geophys. J. R. astr. Soc., 68, 725-750.

Lowry, A.R., Ribe, N.M. \& Smith, R.B., 2000. Dynamic elevation of the Cordillera, western United States, J. geophys. Res., 105(B10), 23,371-23,390.

Macario, A., Malinverno, A. \& Haxby, W.F., 1995. On the robustness of elastic thickness estimates obtained using the coherence method, J. geophys. Res., 100(B8), 15,163-15,172.

Martinec, Z., 1993. A model of compensation of topographic masses, Surv. Geophys., 14, $525-535$.

Martinec, Z., 1994a. The density contrast at the Mohorovičic discontinuity, Geophys. J. Int., $117,539-544$

Martinec, Z., 1994b. The minimum depth of compensation of topographic masses, Geophys. J. Int., 117, 545-554.

McNutt, M., 1980. Implications of regional gravity for state of stress in the Earth's crust and upper mantle, J. geophys. Res., 85(B11), 6377-6396.

McNutt, M.K., 1983. Influence of plate subduction on isostatic compensation in northern California, Tectonics, 2, 399-415.

Molnar, P., England, P.C. \& Jones, C.H., 2015. Mantle dynamics, isostasy, and the support of high terrain, J. geophys. Res., 120, 1932-1957. 
1009

1010

1011

1012

1013

1014

1015

1016

1017

1018

1019

1020

1021

1022

1023

1024

1025

1026

1027

1028

1029

1030

1031

1032

Moritz, H., 1990. The inverse Vening Meinesz problem in geodesy, Geophys. J. Int., 102, $733-738$.

Parker, R.L., 1972. The rapid calculation of potential anomalies, Geophys. J. R. astr. Soc., 31, 447-455.

Pavlis, N.K. \& Rapp, R.H., 1990. The development of an isostatic gravitational model to degree 360 and its use in global gravity modelling, Geophys. J. Int., 100, 369-378.

Pavlis, N.K., Holmes, S.A., Kenyon, S.C. \& Factor, J.K., 2012. The development and evaluation of the Earth Gravitational Model 2008 (EGM2008), J. geophys. Res., 117, B04406, doi:10.1029/2011JB008916.

Pérez-Gussinyé, M. \& Watts, A.B., 2005. The long-term strength of Europe and its implications for plate-forming processes, Nature, 436, 381-384.

Perry, H.K.C., Eaton, D.W.S. \& Forte, A.M., 2002. LITH5.0: a revised crustal model for Canada based on Lithoprobe results, Geophys. J. Int., 150, 285-294.

Pratt, J.H., 1855. On the attraction of the Himalaya Mountains, and of the elevated regions beyond them, upon the plumb-line in India, Phil. Trans. R. Soc. Lond., 145, 53-100.

Rapp, R.H., 1982. Degree variances of the Earth's potential, topography and its isostatic compensation, Bull Géod, 56, 84-94.

Rapp, R.H., 1989. The decay of the spectrum of the gravitational potential and the topography for the Earth, Geophys. J. Int., 99, 449-455.

Rummel, R., Rapp, R.H., Sünkel, H. \& Tscherning, C.C., 1988. Comparisons of Global Topographic/Isostatic Models to the Earth's Observed Gravity Field, Ohio State University Report 388, Department of Geodetic Science and Surveying, Ohio State University.

Saupe, D., 1988. Algorithms for random fractals, in The Science of Fractal Images, pp. 71136, eds Peitgen, H.-O. \& Saupe, D., Springer. 
1033

1034

1035

1036

1037

1038

1039

1040

1041

1042

1043

1044

1045

1046

1047

1048

1049

1050

1051

1052

1053

1054

1055

1056

Simons, F.J., Zuber, M.T. \& Korenaga, J., 2000. Isostatic response of the Australian lithosphere: estimation of effective elastic thickness and anisotropy using multitaper spectral analysis, J. geophys. Res., 105(B8), 19,163-19,184.

Simpson, R.W., Jachens, R.C., Blakely, R.J. \& Saltus, R.W., 1986. A new isostatic residual gravity map of the conterminous United States with a discussion on the significance of isostatic residual anomalies, $J$. geophys. Res., 91(B8), 8348-8372.

Sjöberg, L.E., 2009. Solving Vening Meinesz-Moritz inverse problem in isostasy, Geophys. J. Int., 179, 1527-1536.

Sünkel, H., 1985. An Isostatic Earth Model, Ohio State University Report 367, Department of Geodetic Science and Surveying, Ohio State University.

Tiwari, V.M., Diament, M. \& Singh, S.C., 2003. Analysis of satellite gravity and bathymetry data over Ninety-East Ridge: variation in the compensation mechanism and implication for emplacement process, J. geophys. Res., 108(B2), 2109, doi:10.1029/2000JB000047.

Ussami, N., de Sá, N.C. \& Molina, E.C., 1993. Gravity map of Brazil: 2. Regional and residual isostatic anomalies and their correlation with major tectonic provinces, J. geophys. Res., 98(B2), 2199-2208.

Vening Meinesz, F.A., 1931. Une nouvelle methode pour la reduction isostatique regionale de l'intensite de la pesanteur, Bull Géod, 29, 33-51.

Walcott, R.I., 1970. Isostatic response to loading of the crust in Canada, Can. J. Earth Sci., 7, 716-727.

Watts, A.B., 1978. An analysis of isostasy in the world's oceans: 1. Hawaiian-Emperor seamount chain, J. geophys. Res., 83(B12), 5989-6004.

Watts, A.B., 2001. Isostasy and Flexure of the Lithosphere, pp. 458, Cambridge University Press. 
Watts, A.B., 2007. An overview, in Treatise on Geophysics, vol. 6, pp. 1-48, ed Schubert, G., 1058 Elsevier.

1059 Watts, A.B. \& Moore, J.D.P., 2017. Flexural isostasy: constraints from gravity and 1060 topography power spectra, J. geophys. Res., 122, 8417-8430.

1061 Watts, A.B. \& Talwani, M., 1974. Gravity anomalies seaward of deep-sea trenches and their 1062 tectonic implications, Geophys. J. R. astr. Soc., 36, 57-90.

1063 Watts, A.B., Lamb, S.H., Fairhead, J.D. \& Dewey, J.F., 1995. Lithospheric flexure and 1064 bending of the central Andes, Earth planet. Sci. Lett., 134, 9-21.

1065 Wieczorek, M.A., 2007. Gravity and topography of the terrestrial planets, in Treatise on 1066 Geophysics, vol. 10, pp. 165-206, ed Schubert, G., Elsevier.

1067 Wyer, P. \& Watts, A.B., 2006. Gravity anomalies and segmentation at the East Coast, USA 1068 continental margin, Geophys. J. Int., 166, 1015-1038.

1069 Zuber, M.T., Bechtel, T.D. \& Forsyth, D.W., 1989. Effective elastic thickness of the 1070 lithosphere and the mechanisms of isostatic compensation in Australia, J. geophys. Res., 1071 94(B7), 9353-9367. 
1073 Table 1. Values of constants and parameters used in this study. Throughout the article the 1074 following density contrasts are used: $\Delta \rho_{0}=\rho_{c}-\rho_{f}$ and $\Delta \rho_{1}=\rho_{m}-\rho_{c}$.

1075

\begin{tabular}{|l|l|l|}
\hline Constant & Symbol & Value \\
\hline Gravitational constant & $\mathcal{G}$ & $6.67259 \times 10^{-11} \mathrm{~m}^{3} \mathrm{~kg}^{-1} \mathrm{~s}^{-2}$ \\
\hline Young's modulus & $E$ & $100 \mathrm{GPa}$ \\
\hline Poisson's ratio & $v$ & 0.25 \\
\hline Gravity acceleration & $g$ & $9.79 \mathrm{~ms}^{-2}$ \\
\hline Fluid density (air or sea & $\rho_{f}$ & 0 or $1030 \mathrm{~kg} \mathrm{~m}^{-3}$ \\
\hline water) & & $2800 \mathrm{~kg} \mathrm{~m}^{-3}$ \\
\hline Crust density & $\rho_{c}$ & $3300 \mathrm{~kg} \mathrm{~m}^{-3}$ \\
\hline Mantle density & $\rho_{m}$ & \\
\hline
\end{tabular}



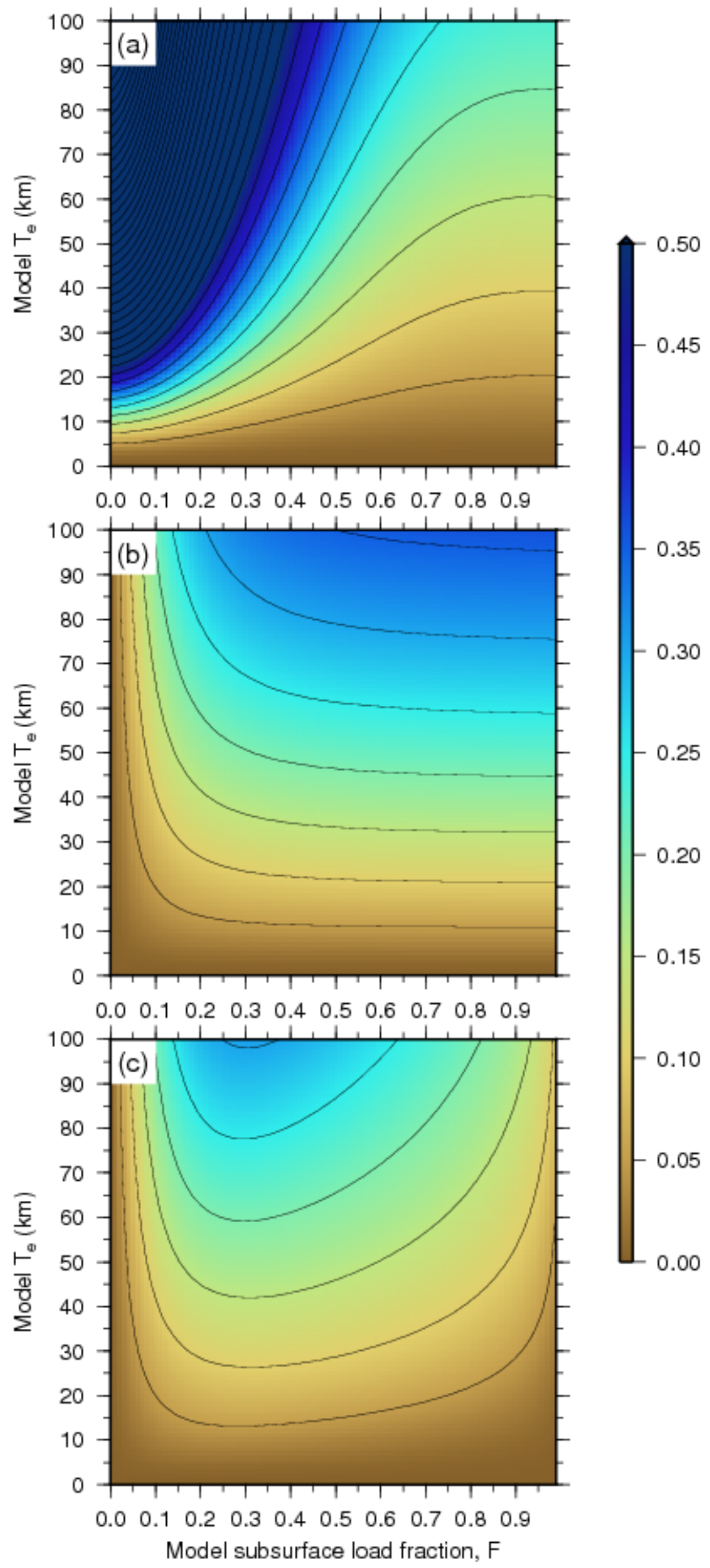
1080 Figure 1. The ratio of the isostatic anomaly standard deviation to that of the corresponding 1081 Bouguer anomaly $\left(\bar{\sigma}_{I A}\right)$, from tests A, B and C. (a) Test A: synthetic models generated with 1082 the $T_{e}$ and $F$ values shown on the axes, and a compensation depth of $z_{m}=35 \mathrm{~km}$;

1083 compensation attraction computed by incorrectly assuming Airy isostasy $\left(T_{e}=F=0\right)$, but the 1084 correct compensation depth. (b) Test B: synthetic models generated with the $T_{e}$ and $F$ values 1085 shown on the axes, and a compensation depth of $z_{m}=35 \mathrm{~km}$; compensation attraction 1086 computed by incorrectly assuming surface loading $(F=0)$, but with the correct $T_{e}$ and 1087 compensation depth. (c) Test C: synthetic models generated with the $T_{e}$ and $F$ values shown 1088 on the axes, and a compensation depth of $z_{m}=35 \mathrm{~km}$; compensation attraction computed by 1089 correctly estimating $T_{e}, F$ and compensation depth. Contour interval in all images is 0.05 , and 1090 the maximum values of $\bar{\sigma}_{I A}$ in each of the panels are: (a) 2.14, (b) 0.36 , (c) 0.30 . 


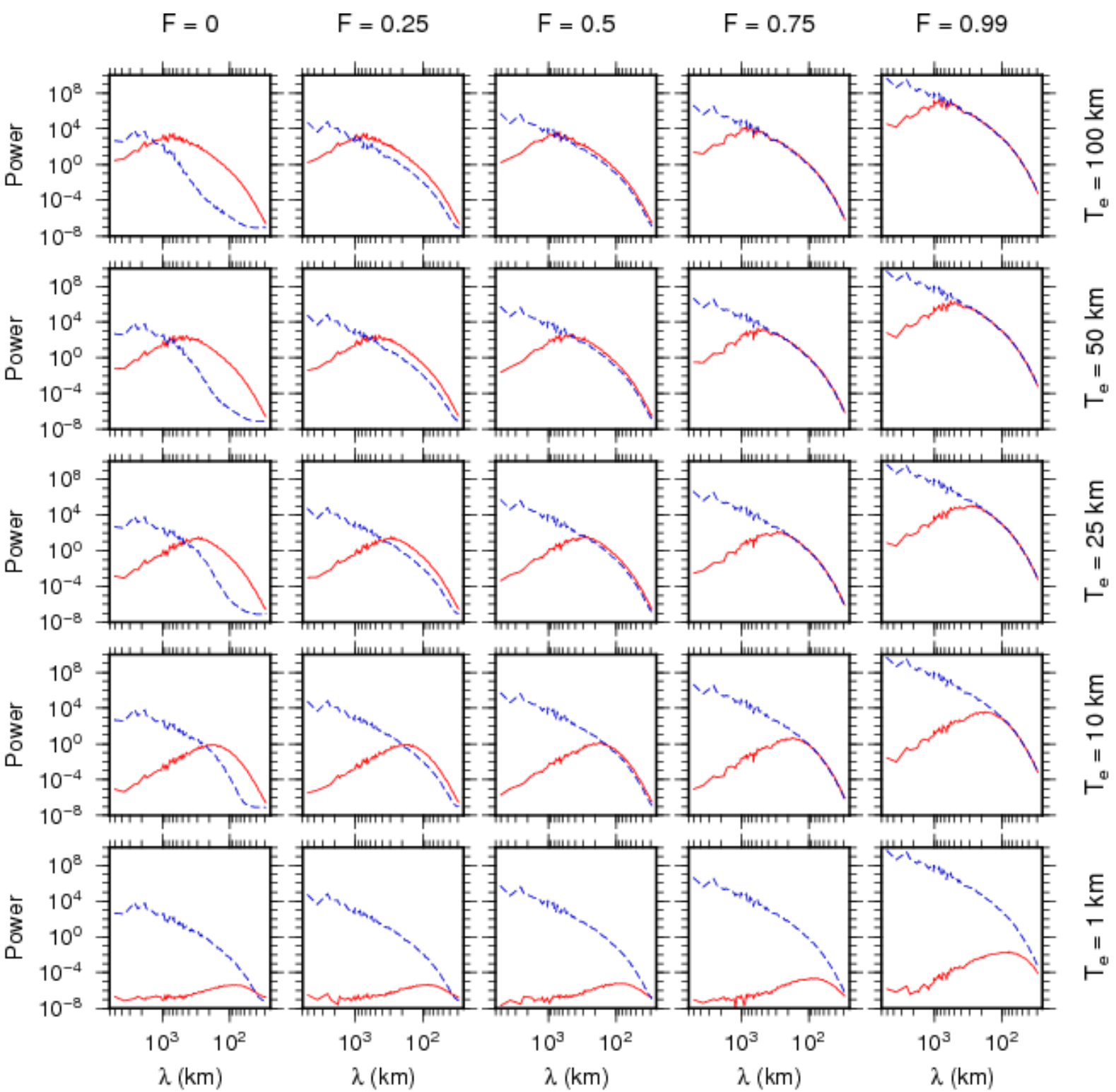

1093

1094 Figure 2(a). Power spectra (versus wavelength $\lambda$ ) from some of the models in test A:

1095 synthetic models generated with the $T_{e}$ and $F$ values shown on the axes, and a compensation

1096 depth of $z_{m}=35 \mathrm{~km}$; compensation attractions computed by incorrectly assuming Airy

1097 isostasy $\left(T_{e}=F=0\right)$, but the correct compensation depth. Bouguer anomaly (blue dashed);

1098 isostatic anomaly (red). The rows and columns correspond to the synthetic model $T_{e}$ and $F$

1099 values in Fig. 1(a). The power spectra in this study were estimated by first computing 2-D

1100 power spectra using Slepian multitapers ( $K=1$ taper) of bandwidth parameter NW $=1$ (e.g.

1101 Simons et al. 2000). Then, the 2-D power spectra were azimuthally averaged over annuli in 
1102 the wavenumber domain for display as 1-D profiles. The multitaper parameters $K=1$ and $1103 \mathrm{NW}=1$ were chosen to maximise the wavenumber-domain resolution of the spectra (e.g. 1104 Kirby and Swain 2013). For these noise-free, synthetic data such low values of $K$ and NW are 1105 acceptable, though for real data more tapers (higher values of $K$, and therefore also NW) may 1106 be preferable in order to improve the estimation variance (e.g. Simons et al. 2000). 
$\begin{array}{lllll}F=0.01 & F=0.25 & F=0.5 & F=0.75 & F=0.99\end{array}$
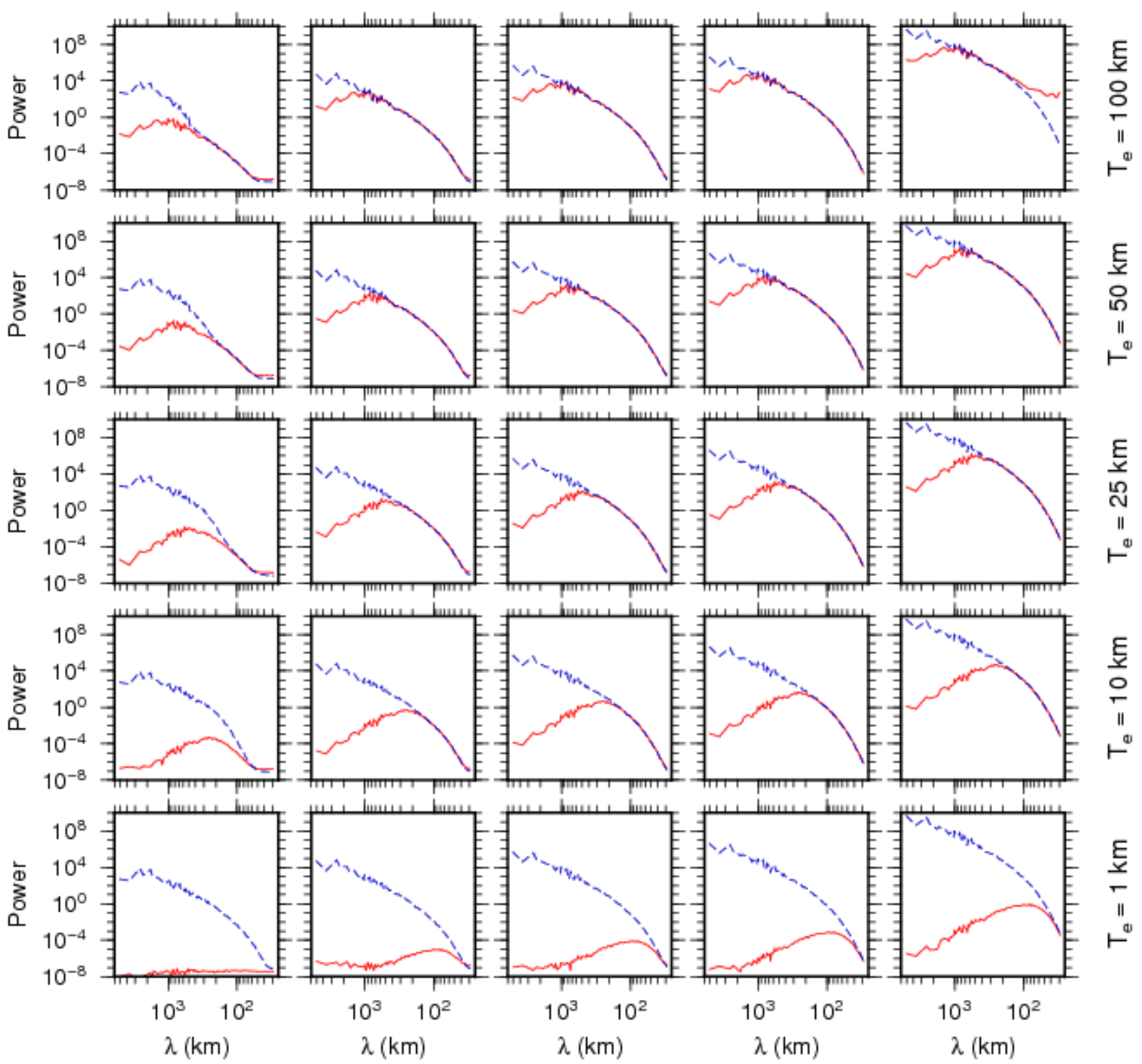

$\frac{E}{\check{E}}$

Figure 2(b). Power spectra (versus wavelength $\lambda$ ) from some of the models in test B:

1111 synthetic models generated with the $T_{e}$ and $F$ values shown on the axes, and a compensation

1112 depth of $z_{m}=35 \mathrm{~km}$; compensation attractions computed by incorrectly assuming surface

1113 loading $(F=0)$, but with the correct $T_{e}$ and compensation depth. Bouguer anomaly (blue

1114 dashed); isostatic anomaly (red). The rows and columns correspond to the synthetic model $T_{e}$

1115 and $F$ values in Fig. 1(b). 
$\begin{array}{lllll}F=0.01 & F=0.25 & F=0.5 & F=0.75 & F=0.99\end{array}$
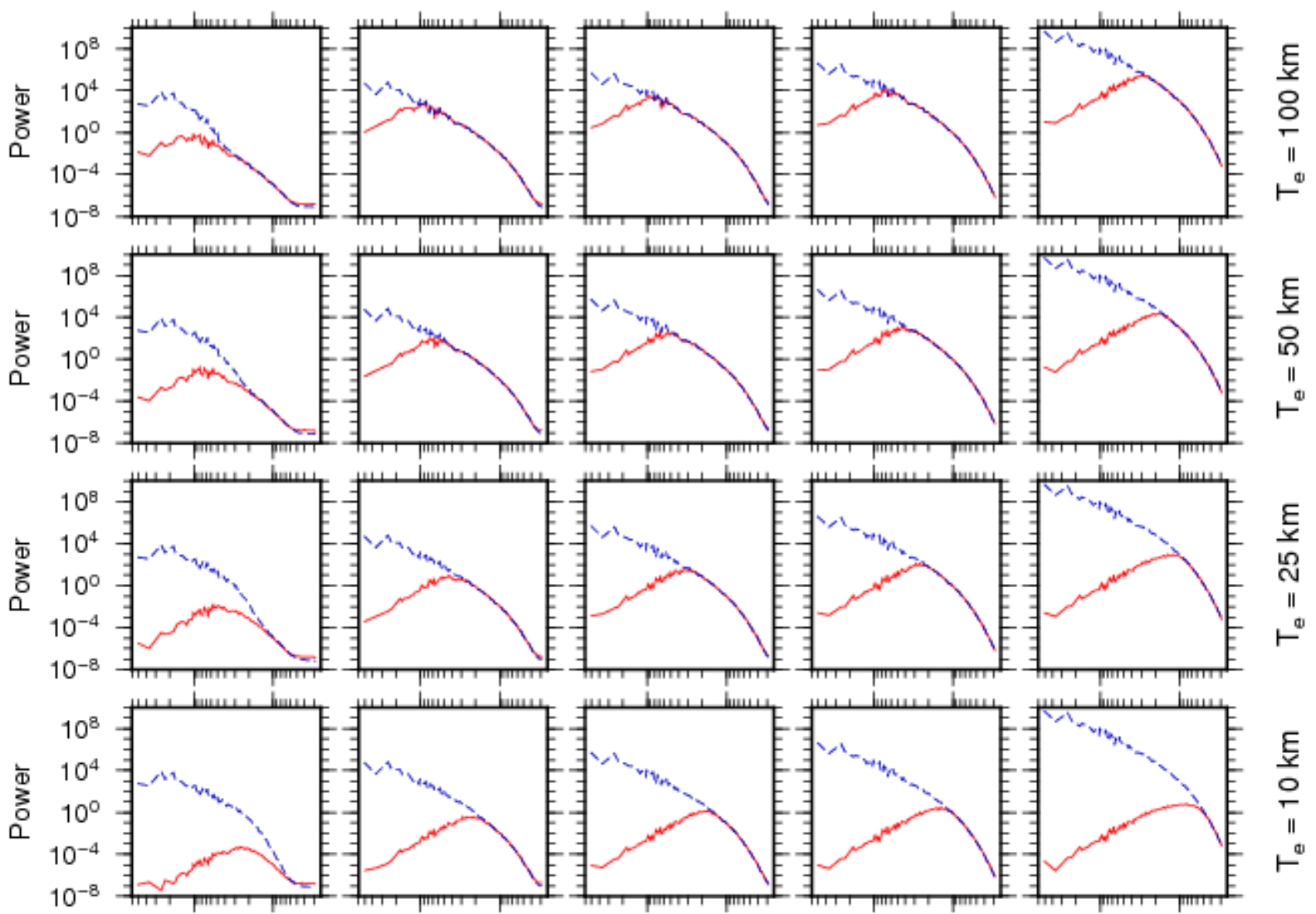

$\frac{\text { 통 }}{ㅁ}$
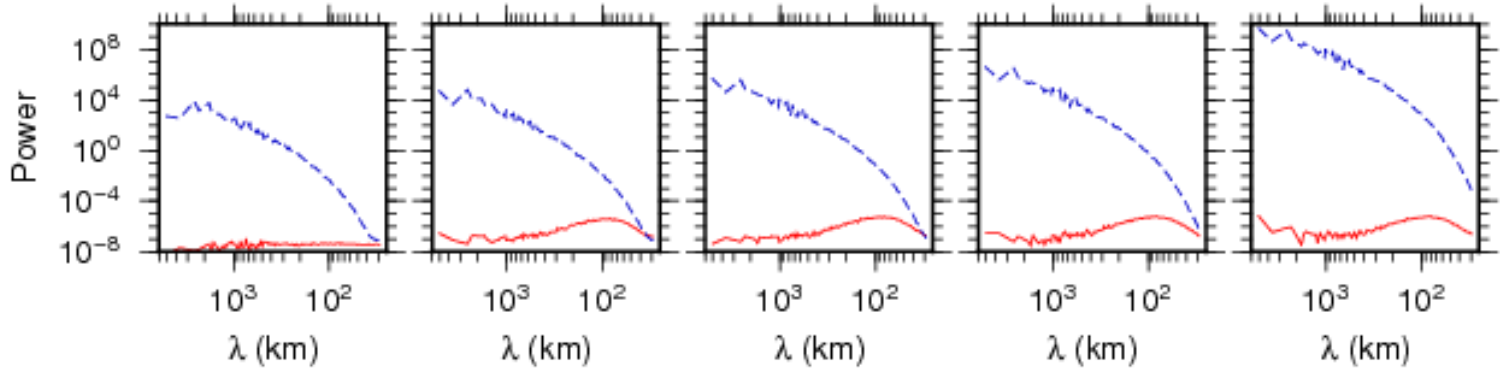

$\frac{\text { E }}{5}$

Figure 2(c). Power spectra (versus wavelength $\lambda$ ) from some of the models in test C:

synthetic models generated with the $T_{e}$ and $F$ values shown on the axes, and a compensation

1121 depth of $z_{m}=35 \mathrm{~km}$; compensation attractions computed by correctly estimating $T_{e}, F$ and

1122 compensation depth. Bouguer anomaly (blue dashed); isostatic anomaly (red). The rows and columns correspond to the synthetic model $T_{e}$ and $F$ values in Fig. 1(c). 


$$
\operatorname{Re}\left(Q_{o b s}\right)(m G a l / k m) \quad I m\left(Q_{o b s}\right)(m G a l / k m)
$$
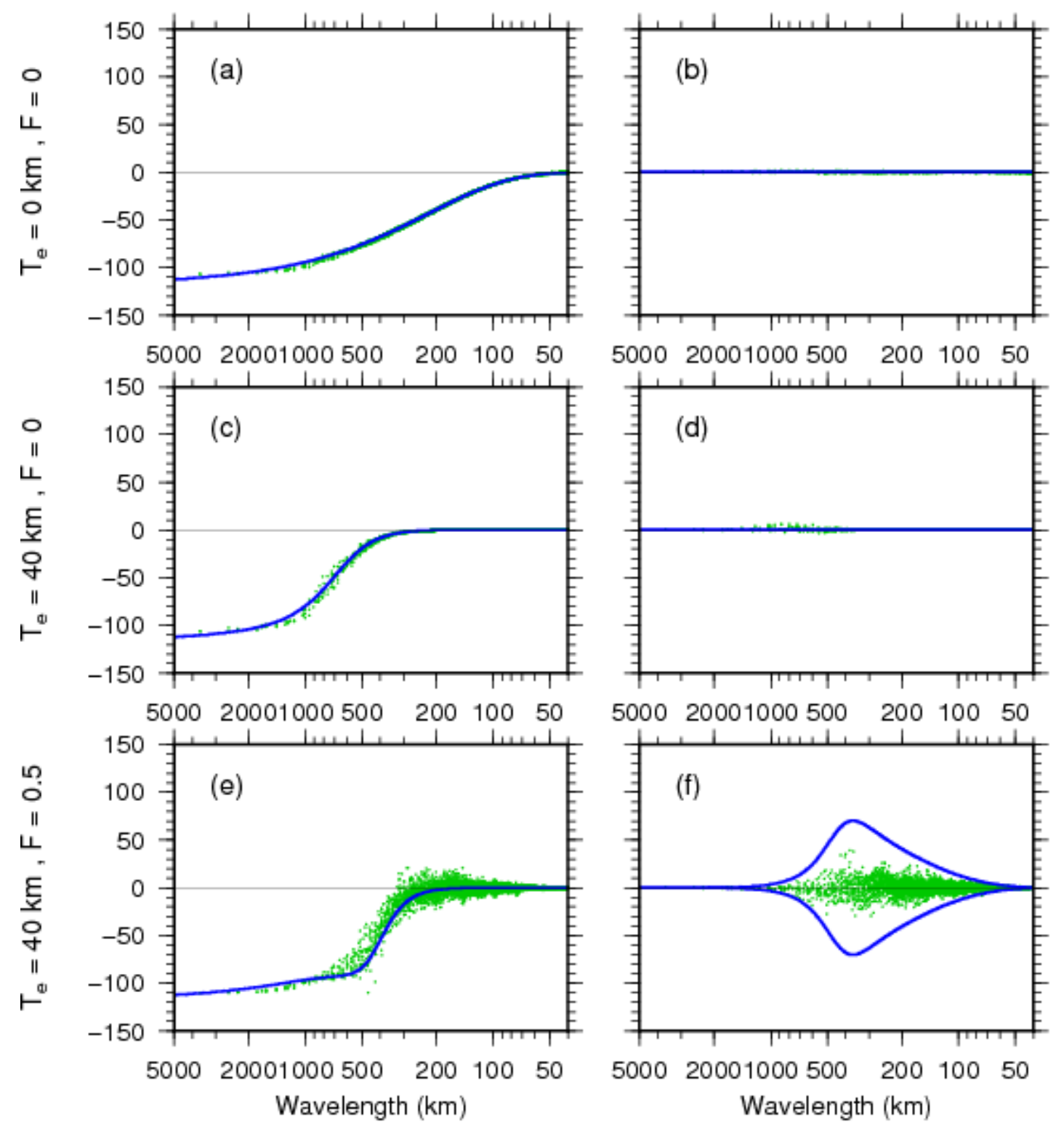

1127 Figure 3. Real and imaginary parts of the observed admittance of the synthetic model

1128 Bouguer anomaly and topography under Airy isostasy ( $a$ and b), surface-only loading (c and

$1129 \mathrm{~d}$ ), and combined loading (e and f). The $T_{e}$ and $F$ values at left are those from which the

1130 models were generated. The green dots show the estimates of the 2-D real and imaginary

1131 observed admittance plotted as functions of their radial wavenumber $k=|\mathbf{k}|$ (but displayed as

1132 wavelength). The blue curves show the theoretical 1-D real and imaginary admittance from

1133 eq. (24) for each $\left(T_{e}, F\right)$ value indicated at left. The theoretical imaginary admittance curve in 
(f) has been reflected about the zero-admittance axis. The auto- and cross-spectra in the

1135 observed admittance were estimated using Slepian multitapers $(K=3, \mathrm{NW}=3)$. It was found

1136 that using $K=1$ taper [as used to compute Fig. 2(a), for example; see Fig. 2 caption]

1137 produced admittance spectra that did not match the theoretical predictions; using 2 or 3 , or an

1138 even higher number of tapers for any value of NW $>2$ resulted in more faithful admittances.

1139 

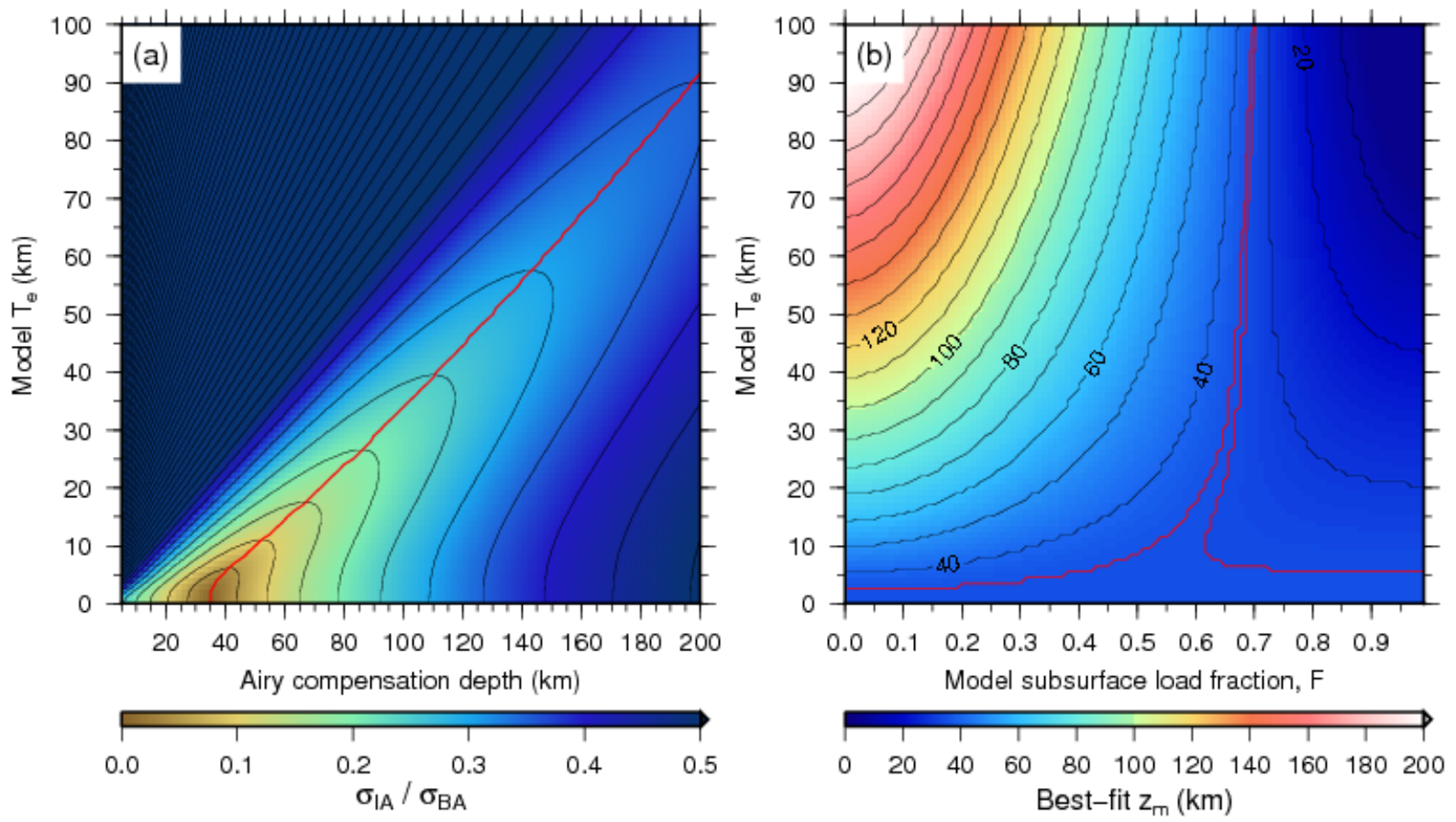

Figure 4. (a) The ratio of the isostatic anomaly standard deviation to that of the corresponding

Bouguer anomaly $\left(\bar{\sigma}_{I A}\right)$. Synthetic models were generated using the $T_{e}$ values shown on the

ordinate, surface-only loading $(F=0)$, and a compensation depth of $z_{m}=35 \mathrm{~km}$;

compensation attraction computed by incorrectly assuming Airy isostasy $\left(T_{e}=F=0\right)$, and

with the compensation depth indicated on the abscissa. The red line in (a) shows the locus of the minimum standard deviation. Contour interval is 0.05 , and the maximum value of $\bar{\sigma}_{I A}$ is

2.26. (b) The value of the best-fitting depth to Moho $\left(z_{m}\right.$, in $\left.\mathrm{km}\right)$ that minimizes the standard deviation of the isostatic anomalies. The synthetic models were generated with the $T_{e}$ and $F$ values shown on the axes (and a compensation depth of $35 \mathrm{~km}$ ); the compensation (and therefore isostatic) anomalies were computed by incorrectly assuming Airy isostasy $\left(T_{e}=F=\right.$ 0) over a broad range of assumed compensation depths (indicated on the abscissa in Fig. 4a).

1153 The two red contours are 34.5 and $35.5 \mathrm{~km}$, and so mark the regions where the model compensation (Moho) depth $(35 \mathrm{~km})$ is recovered almost exactly. Fig. 4(a) hence represents the results from a subset of Fig. 4(b), when $F=0$. 


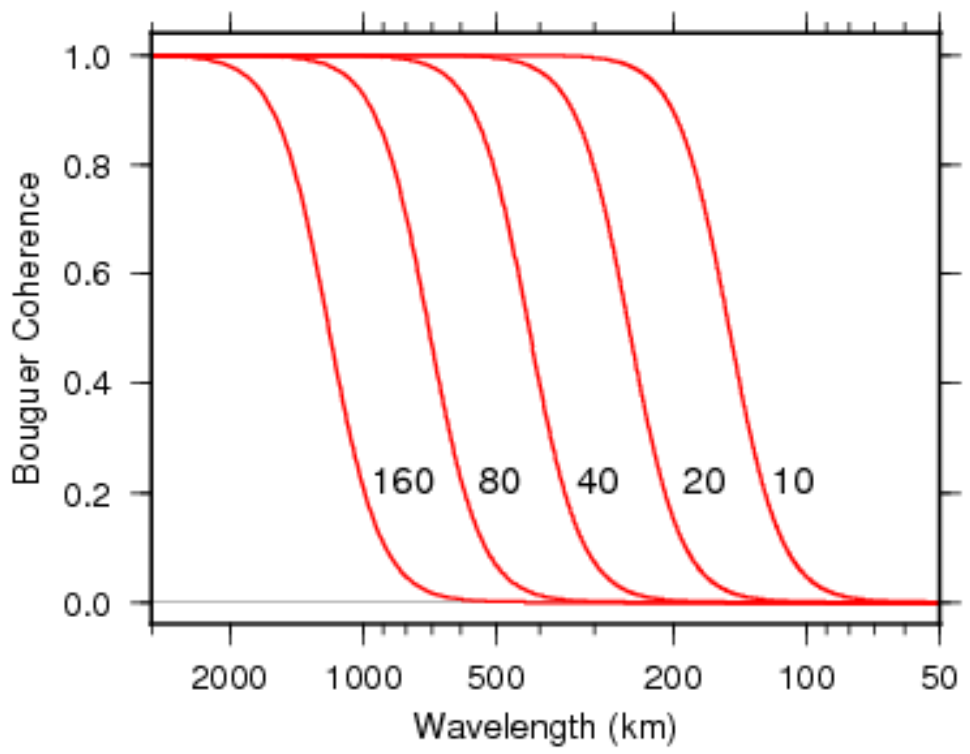

1158 Figure 5. Theoretical curves of the Bouguer coherence for five different $T_{e}$ values (indicated, 1159 in $\mathrm{km}$ ). In all cases the initial loading ratio, $f=1$. Note how lithosphere with a high $T_{e}$ has a 1160 long-wavelength Bouguer coherence rollover (from 1 to 0 ), and as $T_{e}$ decreases the rollover 1161 migrates to shorter wavelengths. 

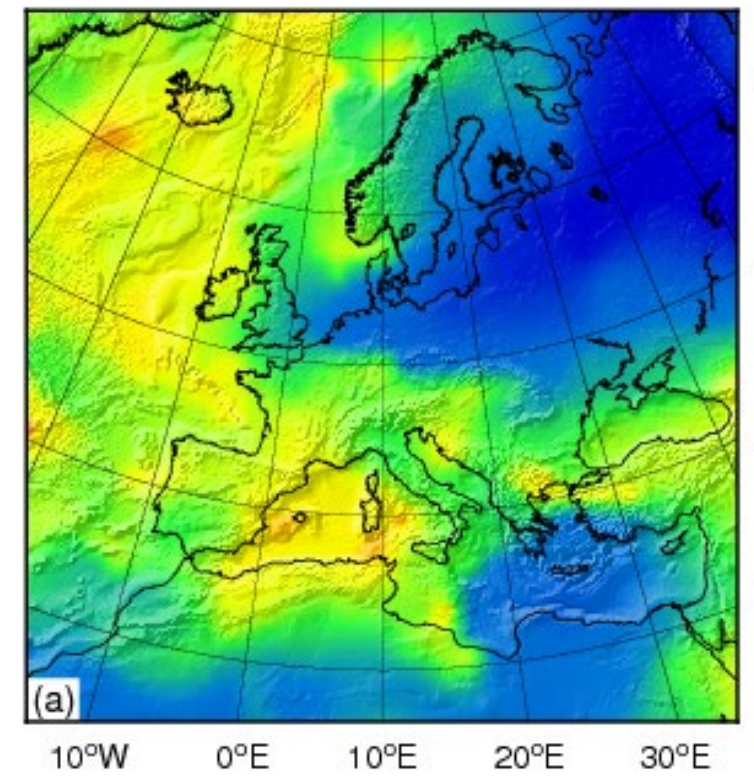

1163

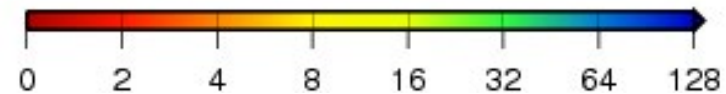

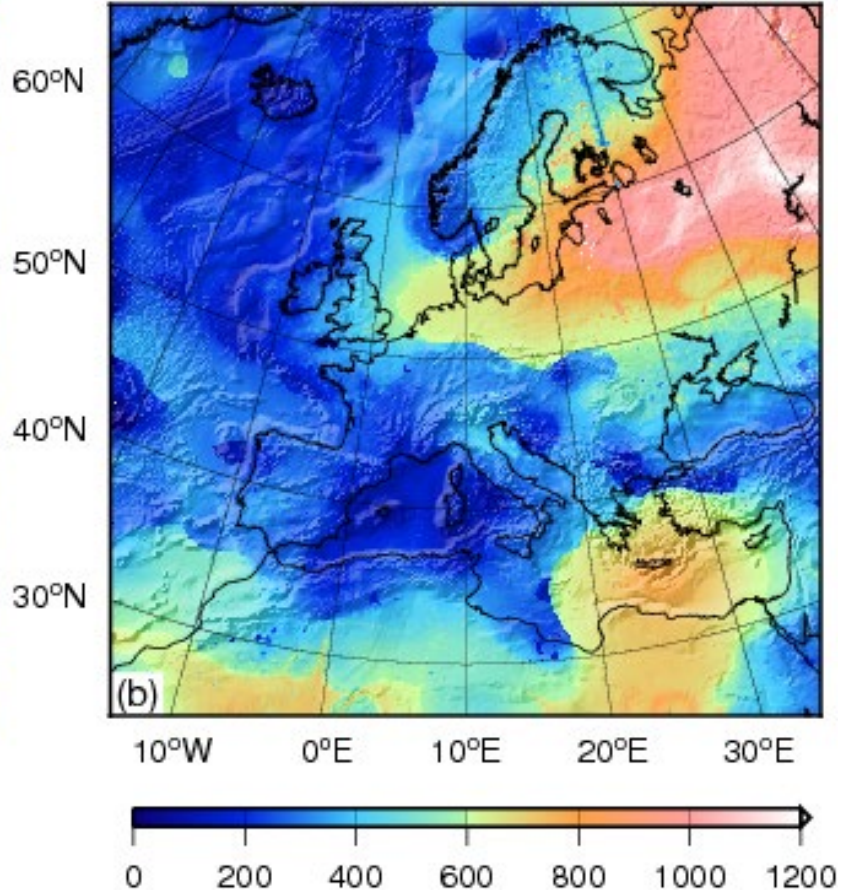

1164

1165 Figure 6. (a) $T_{e}(\mathrm{~km})$, and (b) predicted Bouguer coherence transition wavelength $(\mathrm{km})$ over

1166 Europe, with topography shaded relief superimposed. Lambert conic conformal projection. 

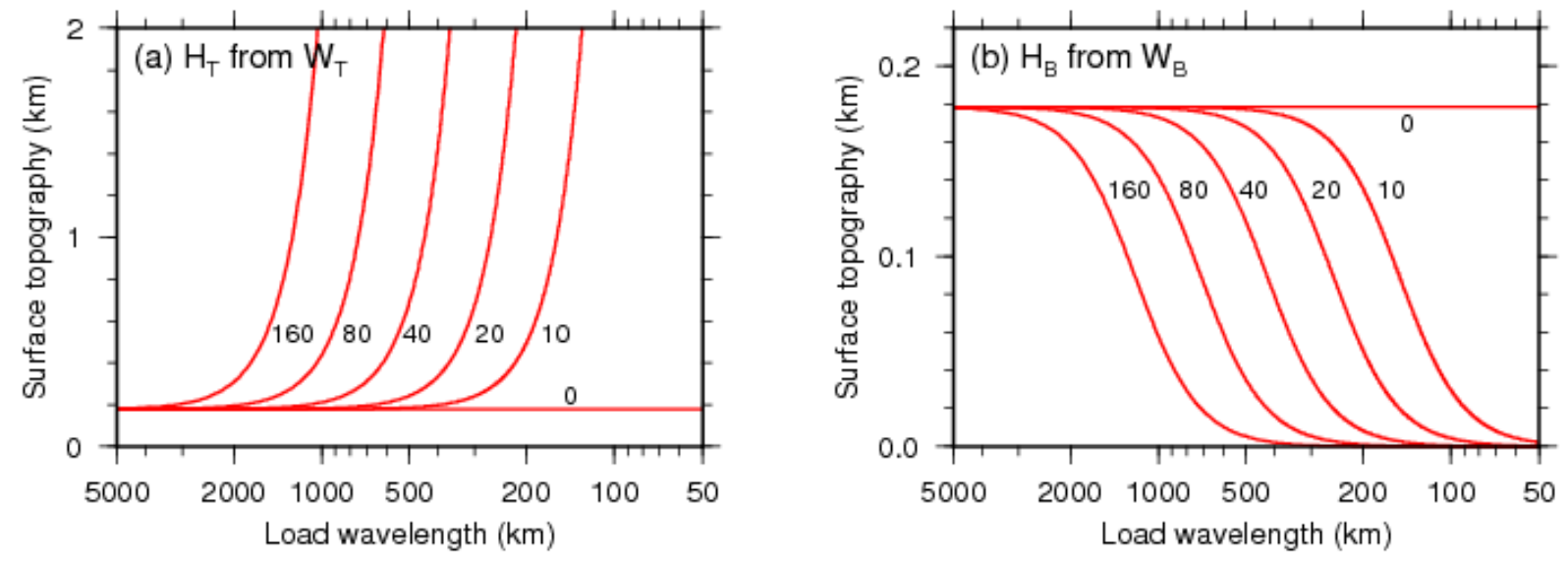

1170 Figure 7. Surface topographic amplitude as a function of load wavelength, corresponding to a

1171 Moho topographic amplitude of $1 \mathrm{~km}$, for six different $T_{e}$ values (indicated, in $\mathrm{km}$ ). (a)

1172 Surface loading, from eq. (31). (b) Subsurface loading, from eq. (33).

1173 